Article

\title{
Future Predictions of Rainfall and Temperature Using GCM and ANN for Arid Regions: A Case Study for the Qassim Region, Saudi Arabia
}

\author{
Khalid Alotaibi ${ }^{1, *}$, Abdul Razzaq Ghumman ${ }^{1}$, Husnain Haider ${ }^{1}$, \\ Yousry Mahmoud Ghazaw ${ }^{1,2}$ and Md. Shafiquzzaman ${ }^{1}$ D \\ 1 Department of Civil Engineering, College of Engineering, Qassim University, Buraydah 51431, \\ Al Qassim, Saudi Arabia; abdul.razzaq@qec.edu.sa (A.R.G.); husnain@qec.edu.sa (H.H.); \\ ghazaw@yahoo.com (Y.M.G.); shafiq@qec.edu.sa (M.S.) \\ 2 Department of Irrigation and Hydraulics, College of Engineering, Alexandria University, \\ Alexandria 21544, Egypt \\ * Correspondence: kkh_01@yahoo.com; Tel.: +966-531-105-001
}

Received: 26 July 2018; Accepted: 13 September 2018; Published: 15 September 2018

\begin{abstract}
Future predictions of rainfall patterns in water-scarce regions are highly important for effective water resource management. Global circulation models (GCMs) are commonly used to make such predictions, but these models are highly complex and expensive. Furthermore, their results are associated with uncertainties and variations for different GCMs for various greenhouse gas emission scenarios. Data-driven models including artificial neural networks (ANNs) and adaptive neuro fuzzy inference systems (ANFISs) can be used to predict long-term future changes in rainfall and temperature, which is a challenging task and has limitations including the impact of greenhouse gas emission scenarios. Therefore, in this research, results from various GCMs and data-driven models were investigated to study the changes in temperature and rainfall of the Qassim region in Saudi Arabia. Thirty years of monthly climatic data were used for trend analysis using Mann-Kendall test and simulating the changes in temperature and rainfall using three GCMs (namely, HADCM3, INCM3, and MPEH5) for the A1B, A2, and B1 emissions scenarios as well as two data-driven models (ANN: feed-forward-multilayer, perceptron and ANFIS) without the impact of any emissions scenario. The results of the GCM were downscaled for the Qassim region using the Long Ashton Research Station's Weather Generator 5.5. The coefficient of determination $\left(R^{2}\right)$ and Akaike's information criterion (AIC) were used to compare the performance of the models. Results showed that the ANNs could outperform the ANFIS for predicting long-term future temperature and rainfall with acceptable accuracy. All nine GCM predictions (three models with three emissions scenarios) differed significantly from one another. Overall, the future predictions showed that the temperatures of the Qassim region will increase with a specified pattern from 2011 to 2099, whereas the changes in rainfall will differ over various spans of the future.
\end{abstract}

Keywords: climate change; GCM; HADCM3; INCM3; MPEH5; ANN; Qassim region

\section{Introduction}

Global climatic change is affecting water resources and several other aspects of life in many developed and developing countries. Research on climate change due to global warming has achieved high importance over the past few decades [1-7]. The magnitude of climatic changes including variations in temperature and rainfall differs in various parts of the world $[4,5,8,9]$. Consequently, some arid regions are expected to experience droughts while others may be affected by heavy rainfalls. For example, the rates of warming and sea level rise are faster than the mean global rate in China [5]. 
According to Bathiany et al. [8], the variability in temperature increases by up to $10 \%$ per degree centigrade of temperatures change in the Sahel, India, and Southeast Asia and by up to $15 \%$ in Amazonia and Southern Africa. Predicting long-term rainfall patterns is essential for developing effective water conservation strategies and planning stormwater management infrastructure in arid regions.

Mostly, dynamic models have been used in the past for rainfall predictions in different parts of the world. Although stationary models are less complex and time efficient, their effectiveness has not been adequately evaluated thus far. Past studies have either used dynamic models to compare different emission scenarios or stationary models without considering the impact of global warming. Practicality of stationary models has not been evaluated by comparing them with the results of various emission scenarios to see how close their predictions are to the globally recognized dynamic models.

Dynamic models such as Global circulation models (GCMs) and regional climate models have played a significant role in making predicting meteorological and hydrological parameters [6-11]. The simulations are based on highly complex mathematical representations of atmospheric, oceanic, and continental processes. These models can predict future climate patterns for likely future emissions scenarios developed by the Intergovernmental Panel on Climate Change (IPCC) [10]. However, GCMs can simulate the climatic parameters only at grid points which requires downscaling to regional level by regional climate models. Significant uncertainties have been reported in GCM and regional climate models results [1,12-18]. Krysanova et al. [1] reported that an average fraction of uncertainty for the annual-mean-flow predictions for various basins was up to $57 \%$ for GCM and up to $27 \%$ for regional climate models. Gao et al. [13] concluded that climate change models should always be used cautiously because of their uncertainties, due to: (i) the downscaling of broader GCM results to regional levels; (ii) uncertainty in the selection of future emissions scenarios; (iii) identification of parameters for GCMs; (iv) simplification of processes itself on which the results of GCMs are based; (v) data errors; and (vi) size and of dataset [19-22]. The two main types of downscaling techniques including statistical and dynamical downscaling have several further categories. Statistical downscaling techniques are simple but need fine tuning $[23,24]$. Dynamical downscaling requires extensive resources to establish a high resolution grid to accurately interpolate the global simulations into small-scale regional predictions [23-26]. The emissions scenarios are based on expert knowledge and need to be carefully selected [24-27].

The decision makers and planners have to examine various scenarios for risk assessment of water resources projects including climate and non-climate factors [19-22]. Hence, analysis based on stationary climate conditions with no emission scenario may help forming an additional alternative for risk assessment. It can be covered by another dimension of modeling based on data-driven simulation techniques [28-32]. It is worth-mentioning that around 35-40 years of data of the time of industrial boom can implicitly capture one or more of the emission scenarios. Thus, it would be highly useful for decision-makers to see the results from data-driven models under prevailing past conditions. There are several categories of data-driven models including Artificial Neural Networks (ANNs) and ANFISs (adaptive neuro-fuzzy inference systems) [33-39]. ANFISs and ANNs are used for rainfall and temperature analyses [33-39] and these models may perform non-linear regression using various optimization techniques [33-39]. Data-driven models are simple to use and require less time and effort when compared to GCMs (Table 1) [38-43]. These models can efficiently address the non-linearity of systems due to their parallel architecture. ANN especially is considered a modern technique to address signals in engineering fields and have also been used as a calculation tool to solve certain problems concerning water resources $[33,34]$. The other types of data driven models, such as fuzzy logic and genetic algorithms, cannot be used for the long-term predictions due to their logical assumption. They can be used in hybrid approach with ANN models, for optimizing the weights and bias values during the iteration process. However, ANN and ANFIS are trained based on a database and have the ability to make the long-term predictions. Furthermore, performance evaluation of ANFIS and ANN for rainfall predictions in arid regions has not been done thus far. 
ANNs and ANFISs have been applied in some previous studies for short-term simulations [33-39]. Ali et al. [40] for example applied ANN for drought prediction in northern Areas of Pakistan. Mishra et al. [41] used ANN for analysis of rainfall and to predict the flooding situation in northern India. They recommended considering the impact of global warming in future investigations. However, the application of ANNs and ANFISs for long-term predictions is rare. Although the data-driven models have limitations as they cannot include the impact of emissions scenarios, using ANNs for long-term simulations may be an interesting and useful task to develop an alternate scenario for planning, management, and risk assessment of water resource projects.

Table 1. Comparison of GCM with data-driven models.

\begin{tabular}{|c|c|c|c|}
\hline Characteristics & GCM & ANFIS and ANN & Remarks \\
\hline $\begin{array}{l}\text { Computational expenses } \\
\text { (need of high speed } \\
\text { computers and time for } \\
\text { computations) }\end{array}$ & High & Low & $\begin{array}{l}\text { - High computing power is required for GCM } \\
\text { application. Limitations in computing power } \\
\text { may result in inability to appropriately } \\
\text { resolve the important climate processes. } \\
\text { Low-resolution models fail to capture many } \\
\text { important phenomena on regional and lesser } \\
\text { scales such as clouds. Downscaling to } \\
\text { higher-resolution models introduces } \\
\text { boundary interactions that can contaminate } \\
\text { the modeling area and propagate error. } \\
\text { Moderate computing power may function } \\
\text { adequately in ANFIS and ANN. }\end{array}$ \\
\hline $\begin{array}{l}\text { Data and model } \\
\text { processing requirements }\end{array}$ & $\begin{array}{l}\text { Highly } \\
\text { complex }\end{array}$ & $\begin{array}{l}\text { Moderately } \\
\text { complex }\end{array}$ & $\begin{array}{l}\text { Require high resolution downscaling to } \\
\text { convert GCM results into } \\
\text { regional predictions. } \\
\text { Data of a specific region are used to predict } \\
\text { the future patterns of rainfall in ANFIS and } \\
\text { ANN application. }\end{array}$ \\
\hline Model Type & $\begin{array}{l}\text { Physically } \\
\text { distributed }\end{array}$ & Black-box & $\begin{array}{l}\text { - GCMs incorporate many physical processes } \\
\text { involved in determining climate. All the } \\
\text { important chemical and biological processes } \\
\text { that influence climate over long time periods } \\
\text { should also be used. Several of these } \\
\text { processes may either be missing or } \\
\text { inadequately represented in today's } \\
\text { state-of-the-art climate models. } \\
\text { ANFIS and ANN are data-driven models and } \\
\text { do not involve any physical process. These } \\
\text { models use only the observed data during } \\
\text { training and predictions. }\end{array}$ \\
\hline Model bias & Large & Limited & $\begin{array}{l}\text { The biases are of varying magnitude (wide } \\
\text { range of variation) in model projections. } \\
\text { The biases are limited to a certain range in } \\
\text { most cases of data-driven model projections. }\end{array}$ \\
\hline Emission scenarios & $\begin{array}{l}\text { Widespread } \\
\text { applications }\end{array}$ & $\begin{array}{l}\text { Stationary } \\
\text { conditions }\end{array}$ & $\begin{array}{l}\text { - There is a large range magnitude of projected } \\
\text { responses, up to a doubling of } \\
\text { atmospheric- } \mathrm{CO}_{2} \text {, which may result in great } \\
\text { errors in model predictions. } \\
\text { No such process is involved in data-driven } \\
\text { models. This is a limitation of data-driven } \\
\text { models as these cannot include the impact of } \\
\text { various emissions scenarios. }\end{array}$ \\
\hline
\end{tabular}

GCMs have been used to assess the impact of climate change on rainfall either with fewer models or scenarios [1-3]. For instance, Forestieri et al. [42] used only one climate model output to 
analyze the impact of climate for Europe. Saymohammadi et al. [43] predicted climate change impacts on rainfall and temperature using only HadCM3 model under a single emission scenario for Iran. Similarly, Chowdhury and Al-Zahrani [44], DeNicola et al. [45] and Chowdhury [36] investigated the climate-change implications regarding the water resources of Saudi Arabia by predicting temperature and rainfall trends. They only used one model, namely NCAR Community Climate System Model. Changes in temperature and rainfall patterns for the Kingdom of Saudi Arabia by the end of the 21st century have also been studied using a single GCM by Hassan et al and Almazroui [46,47]. The decision makers, as described above, need to develop several scenarios for planning and risk assessment of water resources projects [19-23]. Hence, the main objectives of this paper are: (i) to provide a wide range of future predictions of rainfall based on stationary conditions (using historic data) and various emission scenarios; (ii) to evaluate the performance of data driven models, i.e., ANFIS and ANN for rainfall prediction; (iii) to estimate climate change impacts on temperature, monthly rainfall, and annual rainfall in an arid region; and (iv) to assess the effectiveness of the data driven model by comparing its predicted long-term rainfall with the results of nine different GCM options.

\section{Materials and Methods}

\subsection{Methodological Framework}

This research mainly consisted of four steps. A methodology framework is given in Figure 1. The first step was to collect data regarding daily, monthly and annual temperature and rainfall for the study area. The data used in modeling are average values of these two variables for the whole Qassim area. They were normalized before use in models. The second step was to train/test the ANN/ANFIS models. As per usual practice, some data (e.g., 21 years out of 35 years, i.e., $60 \%$ ) were used for training and remaining for testing and validation. Thus, the data were divided into three parts: $60 \%, 20 \%$, and $20 \%$, respectively, for training, testing, and validation of ANN and ANFIS models. A coding in MATLAB was prepared for ANN and ANFIS to achieve the required objectives. The third step was the application of models for future predictions of temperature and rainfall.

Finally, in the fourth step, the ANN results having no explicit impact of emissions scenarios (only implicitly bringing the impact of changes in historic data into future predictions) were compared with those of the three GCMs with three emissions scenarios. Nine GCM options have produced a wide range of predictions for building scenarios to assess risk and plan the water resources projects. The details of the study area and methods used in the research are described in the following sections.

\subsection{Study Area}

The Qassim region is located between latitudes $25^{\circ} 00^{\prime}$ and $27^{\circ} 00^{\prime} \mathrm{N}$ and longitudes $42^{\circ} 30^{\prime}$ and $45^{\circ} 00^{\prime} \mathrm{E}$. The region lies about $300 \mathrm{~km}$ to the northwest of Riyadh in central Saudi Arabia (Figure 2). Its altitude ranges $600-850 \mathrm{~m}$ above sea level. Qassim has an estimated total area of $80,000 \mathrm{~km}^{2}$ and is divided from the west to the north by Wadi Al-Rummah, which is the longest valley in the Arabian Peninsula with an approximate length of $600 \mathrm{~km}$. The Qassim region is characterized as an important agricultural area in Saudi Arabia due to its fertile soil and groundwater, which forms the main source of water supply [48]. The region lies within an arid zone without renewable surface water, which means that the population has had to adapt to extreme climatic conditions [2]. Qassim mainly falls within the desert climate and is characterized by cold and rainy winters as well as hot summers with low humidity. The temperature ranges $43-49{ }^{\circ} \mathrm{C}$ during the day, and $32-36{ }^{\circ} \mathrm{C}$ at night in summer. The temperature falls to below $0{ }^{\circ} \mathrm{C}$ in winter.

\subsection{Data Collection and Analysis}

Daily, monthly and annual observed data concerning Qassim were collected from the General Authority of Meteorology and Environmental Protection in Jeddah, Saudi Arabia. They represent 
average areal data for the whole Qassim region collected from rain gauges in main cities of the province, namely Buraydah, Unaizah and Al Ras. The main data and their trend analysis results are shown in Figures $3 a-c$ and $4 a, b$. The overall trend in temperature and rainfall variations is described in Section 3.1.1 and 3.1.2. There is a lack of reported in-depth analysis of the Qassim region's rainfall using extensive GCM and ANN modeling thus far [2,43-48]. Due to increasing urban and agricultural water demands, extensive groundwater pumping and drilled wells have reached alarming levels and require serious investigation. Future predictions of rainfall and temperature may greatly aid in the development of water resources to meet future demands. Testing three GCMs under three emissions scenarios and predicting long term results using an ANN represented a daunting but highly useful task for Saudi Arabia in particular, and the international community in general. Only average areal monthly and annual data were used in ANN, ANFIS and GCM.

The data were processed to remove unusual values. This was done using personal experience. Only values such as 7777 or 5555 were removed. Such values were few and were replaced by an average value of rainfall. The maximum and minimum values of temperature and rainfall for each year were identified, and then the average values of annual maximum and minimum temperature and rainfall over a period of 30 years were estimated.

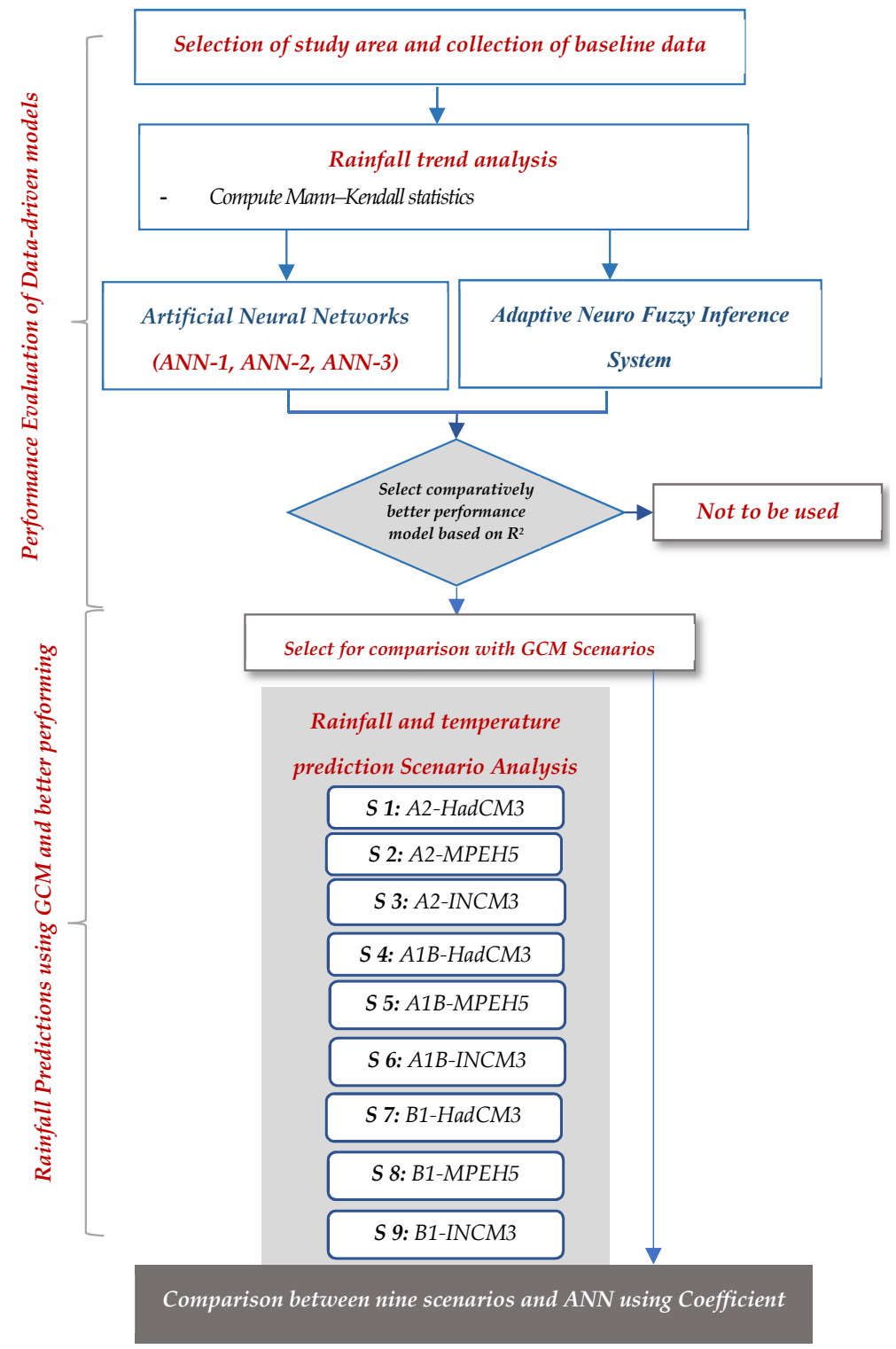

Figure 1. Framework for methodology. 


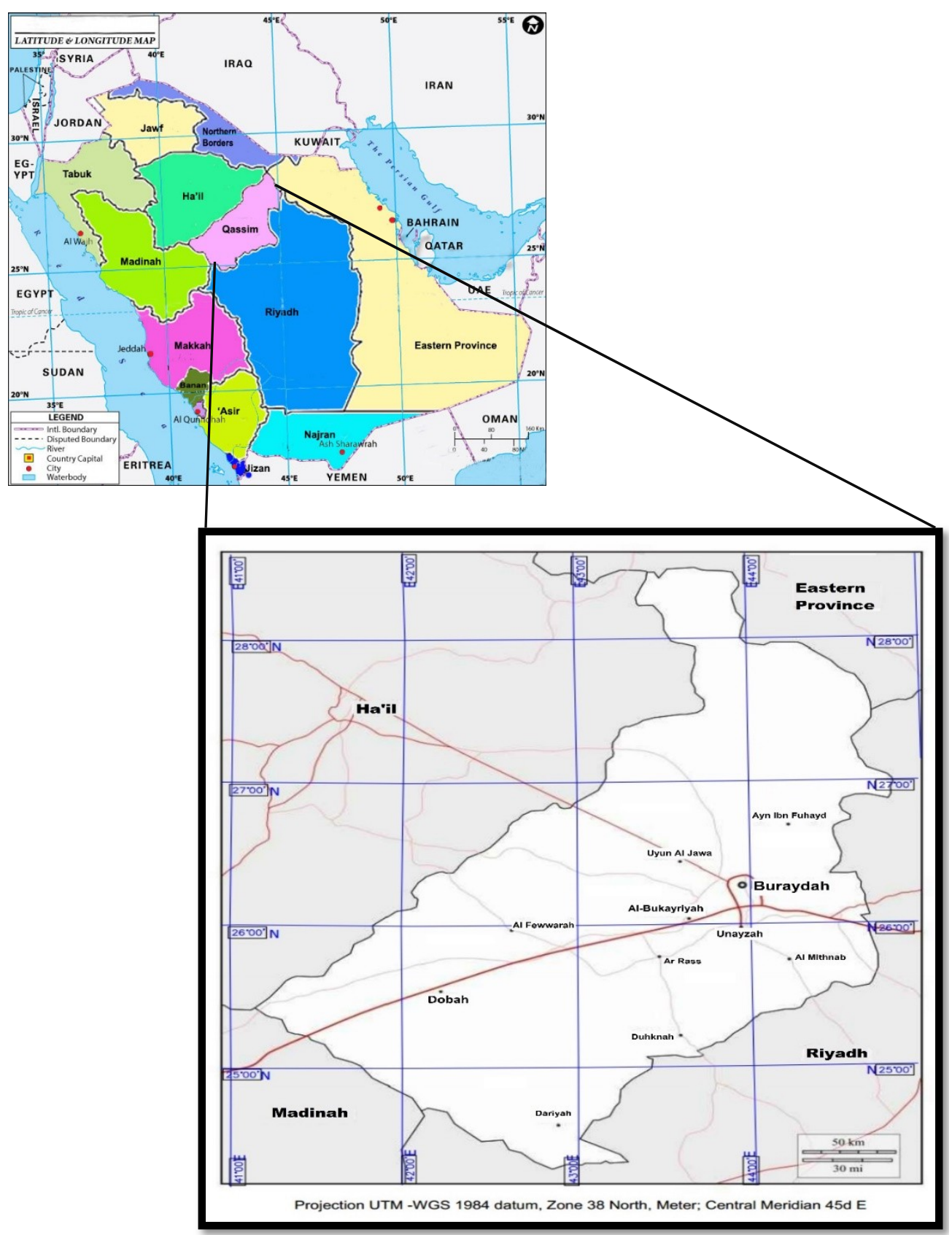

Figure 2. Map showing the location of the Qassim region in the Kingdome of Saudi Arabia.

\subsection{The Mann-Kendall Test for Trend Analysis}

According to the Mann-Kendall test [2], the time series of $n$ data points is divided into $x_{i}$ and $x_{j}$ as two subsets of data where $i=1,2,3, \ldots, n-1$ and $j=\mathrm{i}+1, \mathrm{i}+2, \mathrm{i}+3, \ldots, n$. The Mann-Kendall $S$ statistics is computed as follows [2];

$$
\begin{gathered}
S=\sum_{i=1}^{n-1} \sum_{j=i+1}^{n} \operatorname{Sgn}\left(x_{j}-x_{i}\right) \\
\operatorname{Sgn}\left(x_{j}-x_{i}\right)=\left\{\begin{array}{c}
+1, i f\left(x_{j}-x_{i}\right)>0 \\
0, i f\left(x_{j}-x_{i}\right)=0 \\
-1, i f\left(x_{j}-x_{i}\right)<0
\end{array}\right\}
\end{gathered}
$$




$$
\operatorname{Var}(S)=\frac{n(n-1)(2 n+5)-\sum_{i=1}^{m} t_{i}(i)(i-1)\left(2_{i}+5\right)}{18}
$$

The standard test statistic Zs is calculated as follows:

$$
Z s=\left\{\begin{array}{l}
\frac{S-1}{\sqrt{\operatorname{Var}(S)}} \\
0, S=0 \\
\frac{S+1}{\sqrt{\operatorname{Var}(S)}}, S<0
\end{array}\right\}
$$

The test statistic Zs indicates the significance of the trend. It takes only those values which are significant as a trend for a certain significance level. The values of $Z s$ are compared with the critical value $(Z c r)$ for the significance level of $5 \%$, which comes out to be \pm 1.96 . If the value of $Z s$ is greater than +1.96 , then there is an increasing trend, and, if the value of $Z s$ is smaller than -1.96 , then the presence of a decreasing trend is assumed.

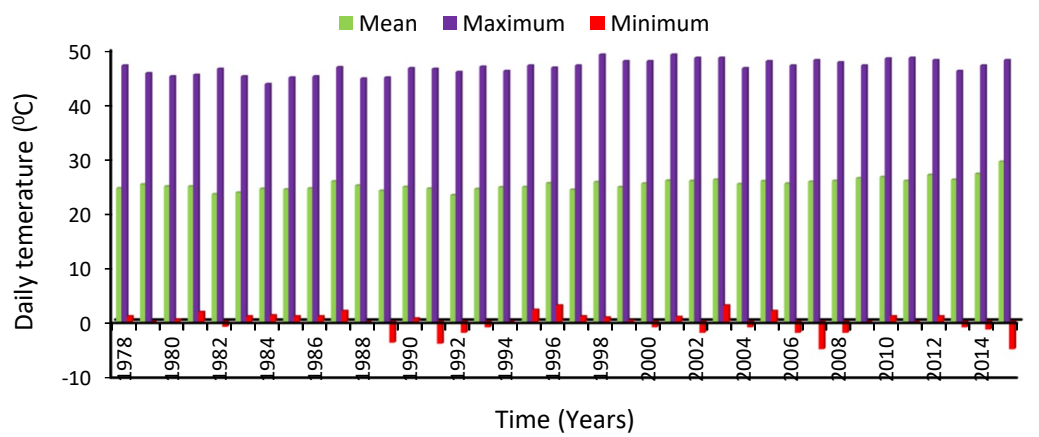

(a)

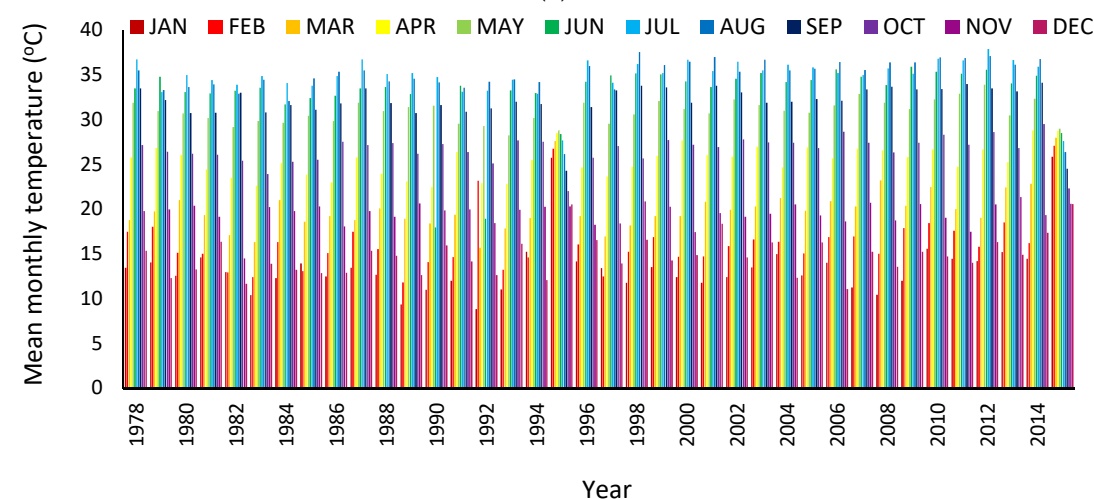

(b)

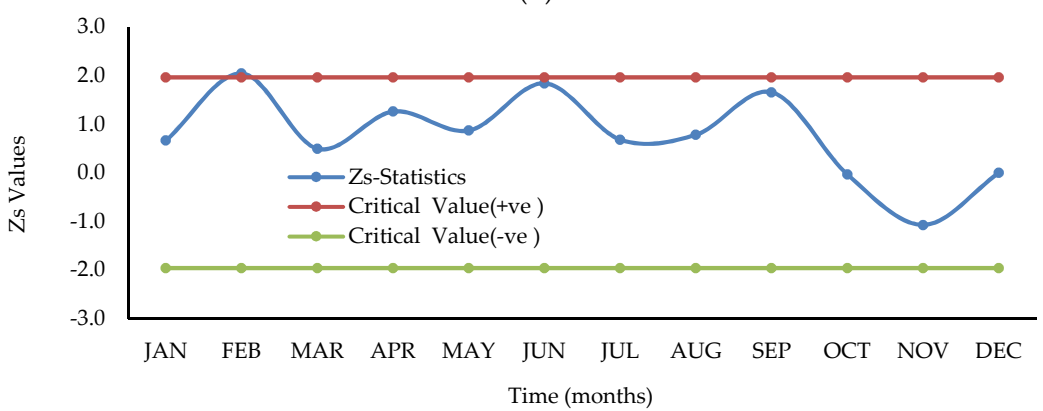

(c)

Figure 3. Mean temperature (observed data) for the Qassim region: (a) mean, maximum and minimum temperature; (b) mean monthly temperature; and (c) trend analysis for temperature (Z-Statistics). 


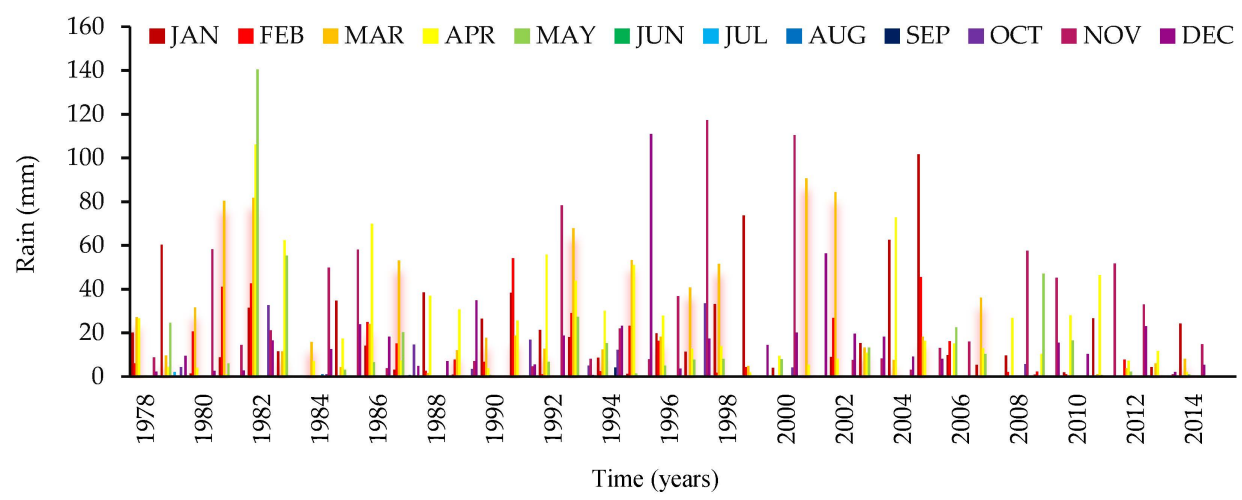

(a)

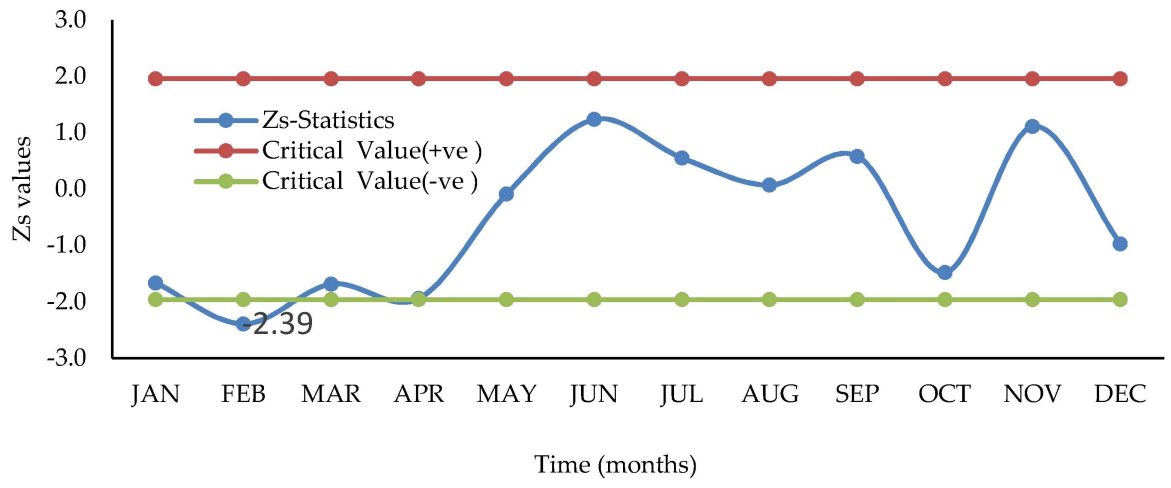

(b)

Figure 4. Rainfall over the Qassim region (observed data): (a) monthly rainfall; and (b) trend analysis for rainfall (Z-Statistics).

\subsection{Artificial Neural Networks (ANN)}

A neural network is a parallel distributed processor comprised of simple processing units with a natural tendency to store experiential knowledge and make it available to humans [49-51]. An ANN is a type of artificial intelligence technique that mimics the behavior of the human brain by the use of neurons. ANNs possess the ability to model linear and non-linear systems without needing to explicitly make assumptions, which is the case in most traditional statistical approaches. ANNs have been applied to various aspects of science and engineering [34,50-52] and can be grouped into two major categories: feed-forward and feedback (recurrent) networks. No loops are formed by the network connections in the former, while, in contrast, one or more loops may exist in the latter. The most commonly used family of feed-forward networks concerns a layered network where neurons are organized into layers with connections strictly in one direction from one layer to another.

\section{Multilayer Perceptron}

Multilayer Perceptrons (MLPs) are the most common type of feed-forward networks [28,29]. Figure 5a shows an MLP with three types of layers: an input layer, an output layer, and a hidden layer. The neurons in the input layer merely act as buffers for distributing the input signals $x_{i}(i=1,2, \ldots, n)$ to neurons in the hidden layer ( $n$ is the total number of input signals). Each neuron $j$ (Figure $5 b$ ) in the hidden layer represents the sum of its input signals $x_{i}$ after weighting them with the strengths of the respective connections $w_{i j}$ from the input layer and computes its output $y_{j}$ as a function $f$ of the sum of $w_{i j} \times x_{i}$. 


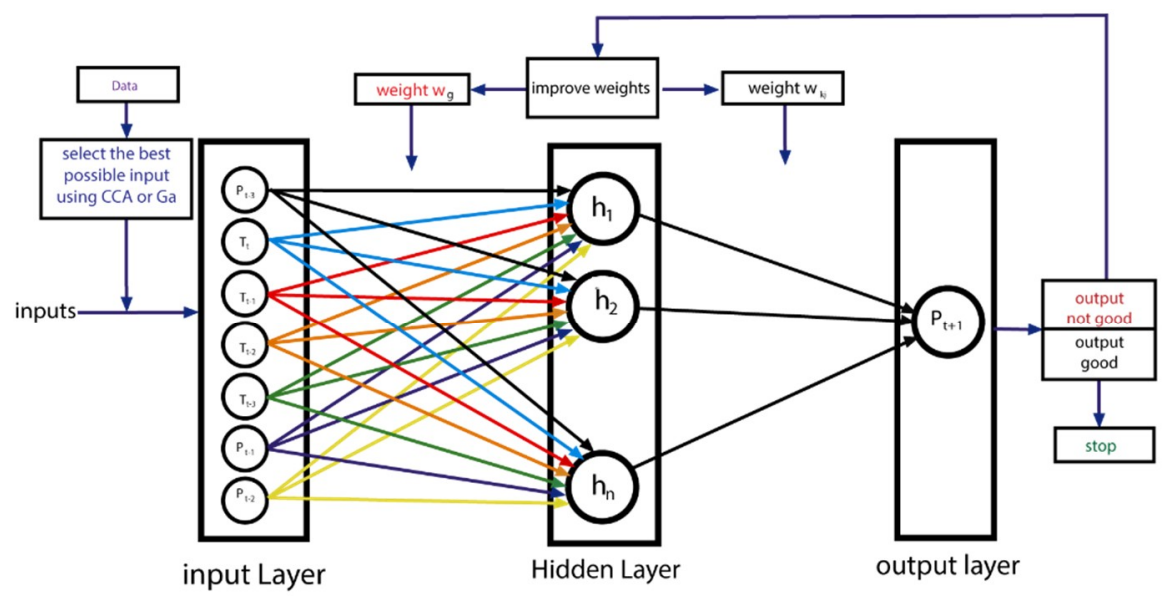

(a)

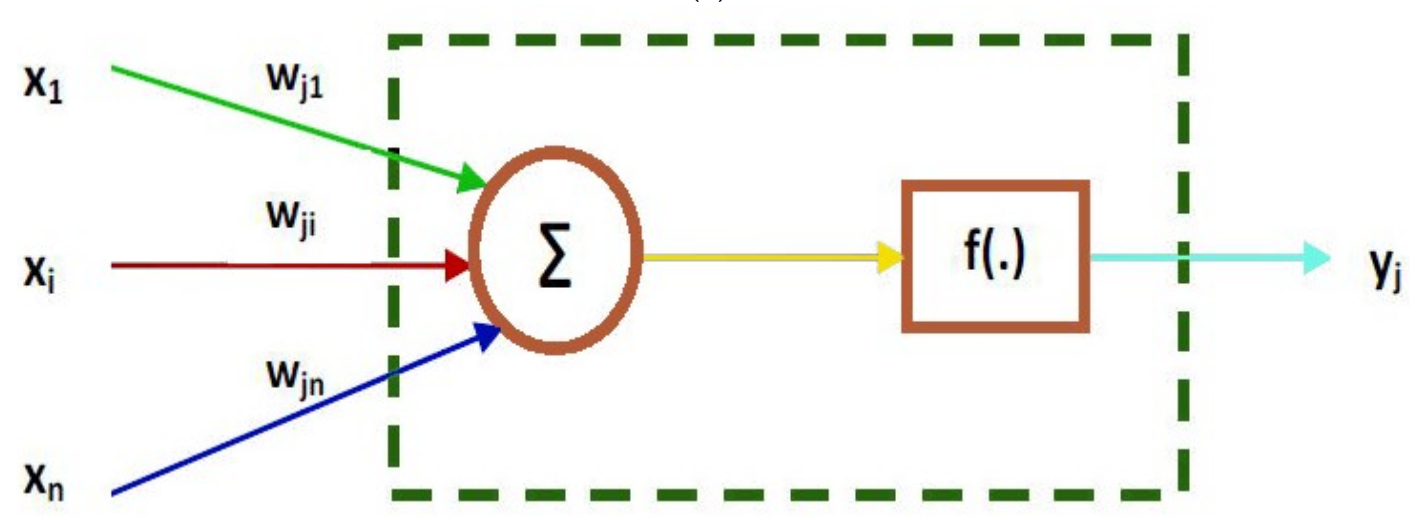

(b)

Figure 5. (a) Flow chart for MLP (a feed-forward ANN); and (b) summation of input signals with weights in neural networking for generating output.

The output of neurons in the output layer is similarly computed. The backpropagation algorithm, a gradient descent algorithm, is the most commonly adopted MLP training algorithm. The design of ANN models follows four primary steps: (1) data preprocessing and defining input parameters; (2) network building; (3) network training; and (4) prediction of results. The monthly rainfall data were normalized as a first step of designing the ANN model used in this research. The number of hidden layers, number of neurons, and transfer function in each layer, training function, and performance function were specified. MLPs and radial basis function (RBF) networks were used. Three ANN architectures (i.e., ANN-1, ANN-2, and ANN-3) were tested with two hidden layers and 5, 10, and 15 neurons specified in each layer. During the training process, the weights were adjusted to align the actual outputs (predicted temperature and rainfall) closer to the target (recorded temperature and rainfall). Own coding in MATLAB was done to develop the ANN for this study to achieve Objectives (i), (ii) and (iv). Most of the built-in transfer functions available in MATLAB were used. Sixty percent and twenty percent of data were used in training and testing, respectively. The performance of the developed model was tested using statistical performance indicators. Finally, the results were generated using an ANN for Qassim up to the year 2099.

\subsection{Adaptive Neuro Fuzzy Inference System}

Data-driven models are gaining high importance [28-31,33,53]. In adaptive fuzzy inference system models (ANFIS), the input-output relation of a real system is described with the help of a set of fuzzy if-then rules. A combination of input variables along with a constant term defines the 
output of each rule. The weighted output average of each rule becomes the final output. The fuzzy systems mainly contain three parts, namely fuzzification, inference, and defuzzification, and are composed of five functional blocks, as shown in Figure 6a $[28,29,53,54]$. The corresponding equivalent ANFIS architecture is shown in Figure 6b,c. Three types of ANFISs were tested with 50, 100, and 500 maximum epochs.

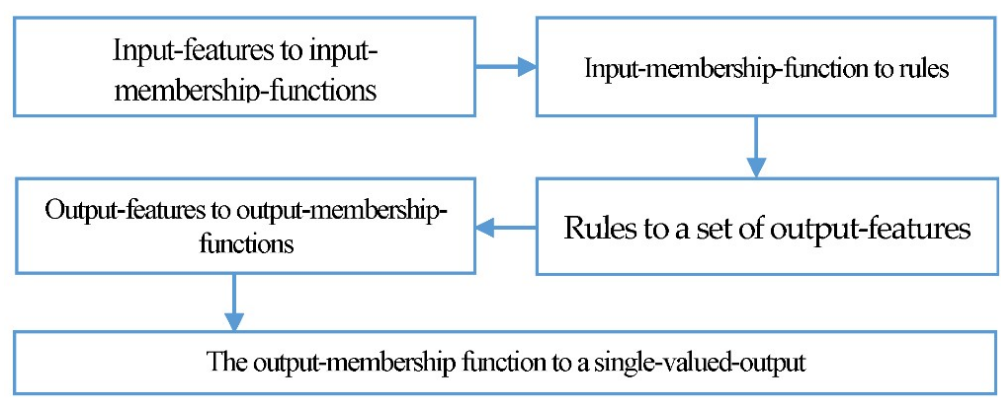

(a)

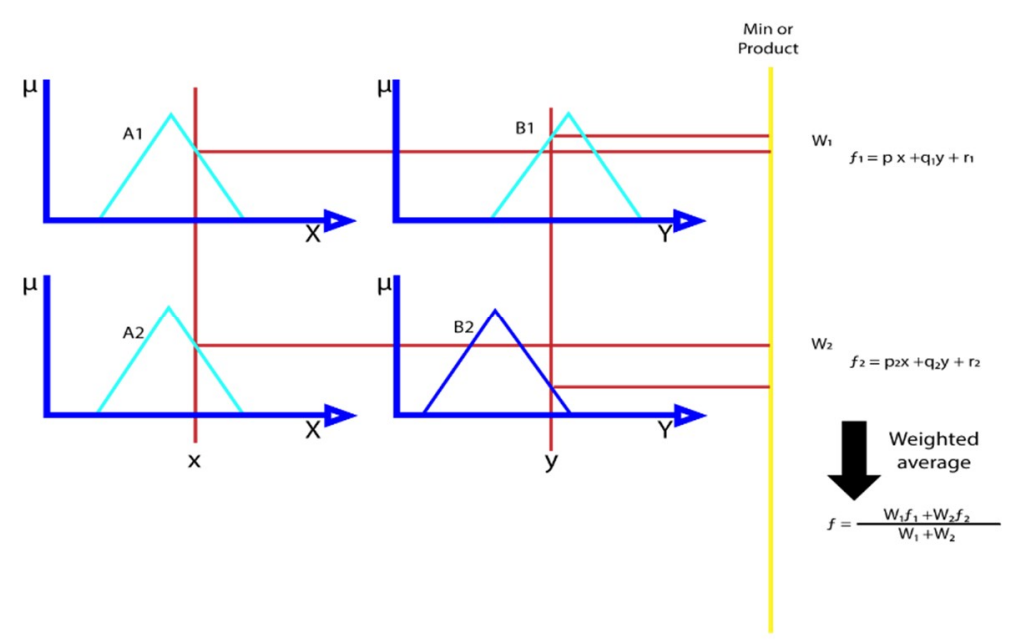

(b)

\section{Layer $1 \quad$ Layer 2 Layer $3 \quad$ Layer 4 Layer 5}

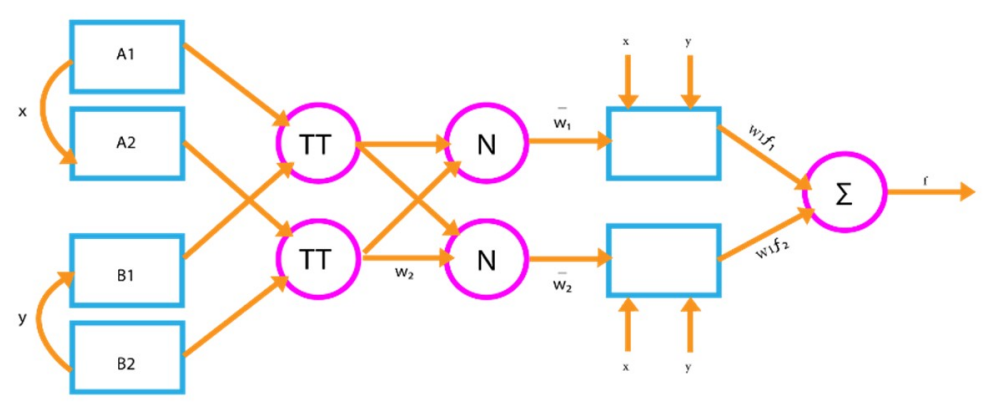

(c)

Figure 6. Adaptive neuro fuzzy inference system: (a) five functional blocks in ANFIS; (b) two-input first-order Sugeno fuzzy model with two rules; and (c) equivalent ANFIS structure.

\subsection{Global Circulation Models (GCM)}

GCMs are highly sophisticated models that can perform complex modeling of the physical, chemical, and biological processes inherent to the climate system [1,3,55-57]. Globally, about 24 GCMs 
are in use. In this research, three models (namely, HADCM3, INCM3, and MPEH5) were used to predict the future rainfall and temperatures of Qassim. The number of GCM grid points for a region depend upon the resolution of the GCM. The resolution of three GCM used in this study is comparatively higher (as described below) so maxim four GCM grid points were available in the present case. The Long Ashton Research Station's Weather Generator 5.5 has in-built facility of downscaling when the resolution of GCM is coarser. The basin-averaged data were calculated using the inverse distance weighting approach [55]. It was assumed that each predicted value of climatic parameter at a GCM grid point has a local influence that diminishes with distance. Greater weight was allotted to the points closer to the predicted location than those farther away. Hence, the name of the method is inverse distance weighted. Some brief information about the models used in this study is provided below.

\subsubsection{Hadley Center Coupled Model Version 3 (HadCM3)}

This model was developed in 1999 and involves predictions that often use a 360-day calendar, where each month is 30 days. The model has a high-resolution grid ( $375 \mathrm{~km} \times 250 \mathrm{~km})$ and can handle a variety of experiments based on the concentration of greenhouse gases (GHG) and sulfate.

\subsubsection{MPEH5}

This model was developed by the Max Planck Institute for Meteorology in Germany. MPEH has a higher grid resolution of $190 \mathrm{~km} \times 220 \mathrm{~km}$ compared to that of HadCM3. Advanced numerical techniques are used to simulate the behavior of the atmosphere, ocean, cryosphere, and biosphere as well as the interaction between these different components of the Earth's system.

\subsubsection{INCM3}

This model belongs to the Institute for Numerical Mathematics in Russia. The grid resolution used was about $500 \mathrm{~km} \times 400 \mathrm{~km}$. This model also offers a variety of experiments related to GHG.

\subsubsection{Emissions Scenarios}

The future projections for the periods 2011-2045, 2046-2079, and 2080-2099 from these GCMs were downscaled using LARS WG 5.5 for three emissions scenarios A1B, A2, and B1 (the details of which can be found in the IPCC-Assessment Report 5 (AR5) and [4,55-59]). A brief explanation of these scenarios is provided below. However, it is worth mentioning here that, to assess climate changes, the IPCC developed six emission scenarios in the early 1990s called IPCC Scenarios 92 (IS92) [4,55-58]. With the passage of time, there was advancement in research on driving forces of emissions and assessment methods. A new set of four emission scenarios based on socioeconomic storylines was published by IPCC which are described in the Special Report on Emissions Scenarios (SRES) [4,55-59]. Another set of emission scenarios, called concentration pathways (RCPs), were developed on the basis of radiative forcing [55,58]. The RCPs consists of RCP2.6 (a very low radiative forcing level), RCP4.5, RCP6.0 (medium stabilization) and RCP8.5 (very high emission). A thorough literature survey and comparison of results from various set of scenarios show that the SRES A1FI and RCP8.5 scenarios are similar, the SRES A2 produces results between those of RCP6.0 and RCP8.5, SRES A1B scenario gives climate changes close to those of RCP6.0 and the SRES B1 is similar to those of RCP4.5. The temperature changes projected with RCP2.6 are found to be lower than that of any of the SRES scenarios. Climate projections using four RCPs formed the basis of the Coupled Model Inter-comparison Project 5 (CMIP5) [55]. These projections were analyzed extensively for the IPCC fifth assessment report [57-59]. According to Sanderson et al. [55], no liking or disliking is attached to the SRES or RCPs. Rather, these are equally plausible representations of future emissions. In fact, future temperature and rainfall projected under the scenarios within a group (SRES or RCPs) may be used to explore the impacts of different policy options on various activities of life. 
- Special Report on Emissions Scenarios (SRES) A2: This emission scenario is related to the extension of increased annual carbon emissions similar to those followed in the recent past. There is no global control on emissions of $\mathrm{CO}_{2}$. Instead of acting as part of a global world, different regions perform in their individual capacity while minding their own interests. There is no control of the population.

- SRES A1B: This scenario is based on integrating various regions and having slight control of the population and their emissions of $\mathrm{CO}_{2}$. This can be considered as a realistic scenario to some extent.

- SRES B1: This emission scenario is based on strong integration between various regions to form a global world. The population and emissions of $\mathrm{CO}_{2}$ are considered to be controlled in a more ecologically friendly world, but one which still experiences steady and strong economic growth.

\subsection{Model Performance}

For model performance and comparison between the ANN and GCM, two statistical parameters were used. The coefficient of determination $\left(R^{2}\right)$ is given as:

$$
R^{2}=\frac{\left(\sum X_{i} Y_{i}-n \overline{X Y}\right)^{2}}{\left(\sum X_{i}^{2}-n \bar{X}^{2}\right)\left(\sum Y_{i}^{2}-n \bar{Y}^{2}\right)}
$$

where $X_{i}$ and $Y_{i}$ are two variables; $\bar{X}$ and $\bar{Y}$ are the mean values of $X$ and $Y ; n$ is the total number of data points; and $i$ varies from 1 to $n$. $X$ represents the simulated values of $P$ or $T$ by the ANN models, and $Y$ represents the values of $P$ or $T$ simulated by the GCM models in various scenarios [60,61].

The following equation has been used to determine Akaike information criterion (AIC):

$$
A I C=n \log (S S E / n)+2 K
$$

where SSE is the sum of squares of errors; $\mathrm{n}$ is the number of data points; and $K$ is the number of parameters (for example, the number of neurons in hidden layers +1 ). This statistical index is combination of error and complexity of the model. A model with comparatively lower AIC values is accurate and comparatively lesser complex.

\section{Results and Discussion}

\subsection{Observed Data}

\subsubsection{Temperature}

Figure 3a shows that the mean daily temperature for the whole observed period (1978-2015) was about $25{ }^{\circ} \mathrm{C}$. The maximum daily temperature approached $49^{\circ} \mathrm{C}$ and the minimum was found to be $-5{ }^{\circ} \mathrm{C}$. Figure $3 \mathrm{~b}$ shows the mean monthly temperature. It is observed that June, July and August are the hot months in Qassim, while December, January and February are the cold months. Tarawneh and Chowdhury [2] reported values close to these results for the central region of Saudi Arabia (Riyadh). The Mann-Kendall test results are shown in Figure 3c. It shows that there is no trend in temperature (all values of $Z$ lie between \pm 1.96 except for that of only one month (February)). A slightly increasing trend in mean monthly temperature $(Z=2.05)$ was detected for the month of February.

\subsubsection{Rainfall}

Figure 4a shows mean areal monthly rainfall in Qassim which indicates that monthly rainfall exceeded $100 \mathrm{~mm}$ in only 5 of 37 years and that the highest monthly rainfall of $140 \mathrm{~mm}$ was observed in 1982. The rainfall pattern appears to have been regular only over the past decade. Rainfall mainly occurs during the months of November-December and January-February-March. The weather during 
the months of April to September is mostly hot and dry. The average annual rainfall from 1978 to 2015 was about $133 \mathrm{~mm}$, while Hasanean and Almazroui [62] reported about $145 \mathrm{~mm}$ based on data analyzed from 1979 to 2009 . The average monthly rainfall during the months November to March is about $19.5 \mathrm{~mm}$, whereas for dry months (April to September) it is only $2.6 \mathrm{~mm}$. The one-day, two-days, and three-days maximum rainfall for Qassim are 86, 92, and $95 \mathrm{~mm}$ respectively. The Mann-Kendall test results are shown in Figure $4 \mathrm{~b}$. It is observed that there is no trend in rainfall (all values of $\mathrm{Z}$ lie between \pm 1.96 except for that of only one month (February)). A decreasing trend in mean monthly rainfall $(Z=-2.39)$ was detected for the month of February.

\subsection{Performance of Models}

The statistical indicators used to assess the performance were estimated using the difference between simulated and observed data as explained in Section 2.6. The performance comparison between the ANN and ANFIS is illustrated in Figure 7. Both the models produced results with reasonable accuracy and are in agreement with past studies $[28,29,53,54]$. ANN-1, with two hidden layers and five neurons, was found to be the better performing model amongst all the ANN and ANFIS models with $R^{2}$ value of 0.89 and AIC value of 136.15. Hereafter, ANN-1 is termed as ANN and has been used for further comparison with GCM scenarios.

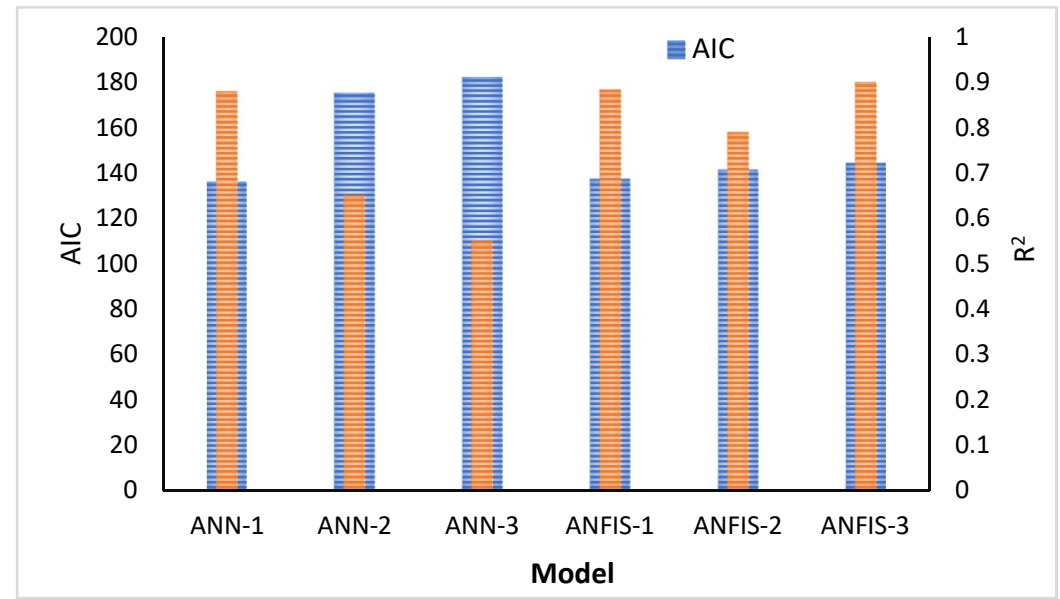

Figure 7. Performance evaluation results of the ANN and ANFIS for rainfall.

\section{Comparison of Models}

Figure 8a-d shows the comparison between the ANN, ANFIS, and GCM models with respect to the correlation between results predicted by the models. The values of $R^{2}$ lie in the range of $0.42-0.63$ in the case of the ANN and ANFIS, and similar trends can be seen in $[28,29,53,54]$. It was observed that the ANNs' predictions only fairly (rather than excellently) matched those of the GCM $\left(R^{2}\right.$ ranged from 0.5 to 0.7 ). However, the results of the ANN could be acceptable as different GCM models also produced highly varied results when compared to one another. Variation in the range of $2-5.7 \%$ in temperature and $20-59 \%$ in rainfall was noticed as compared to the base period. As discussed above, the uncertainties and variation of results from one GCM model to another can be seen in [1,3,11-13]. An uncertainty in the range of $57 \%$ was reported by Krysanova et al. [1] when they applied GCM to various catchments. 


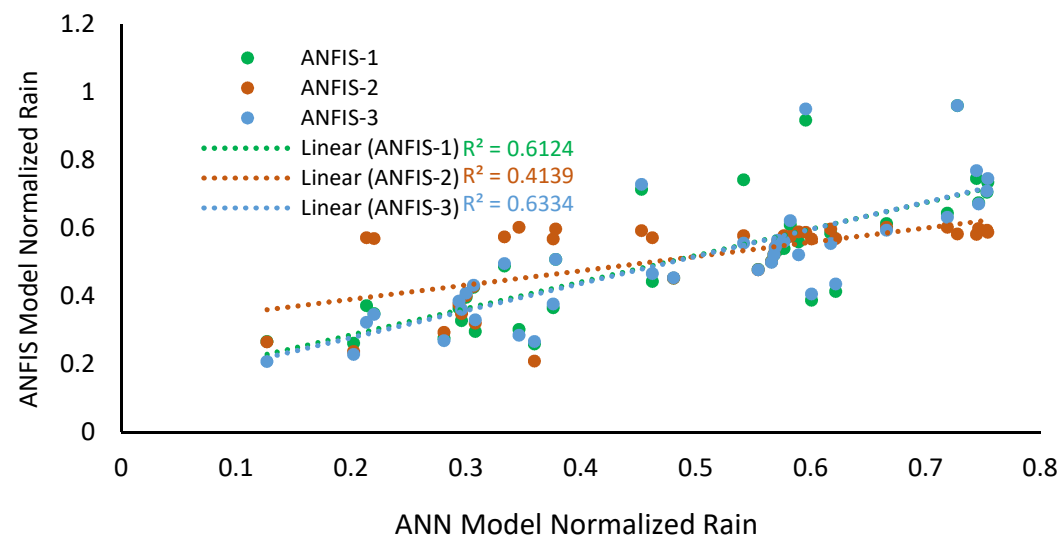

(a)

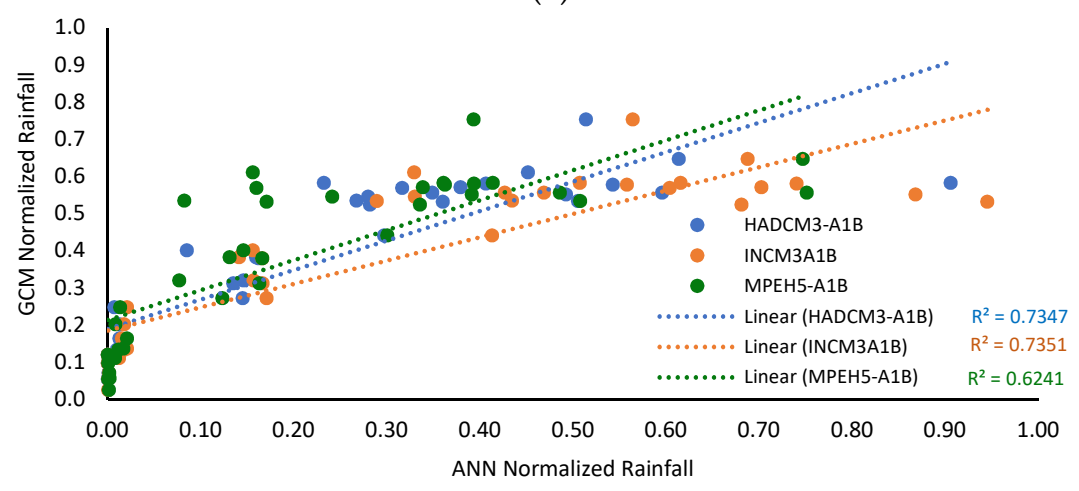

(b)

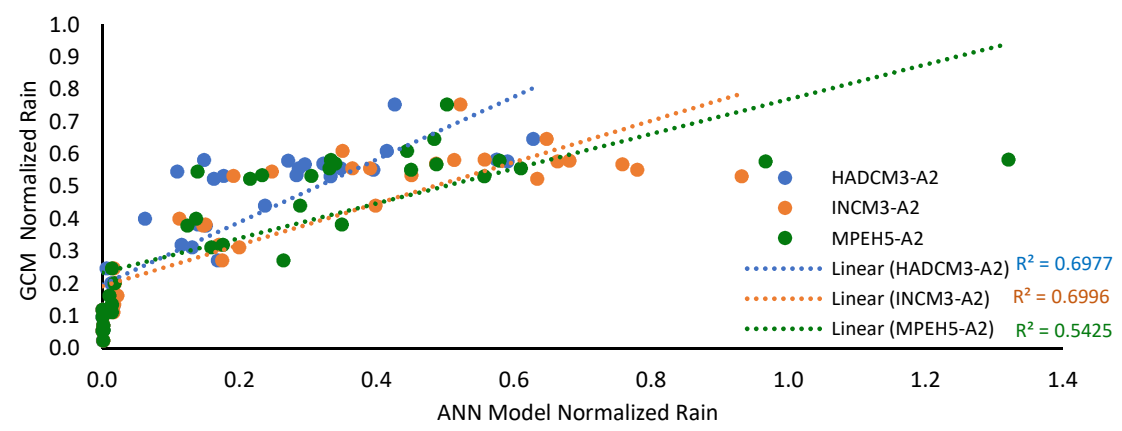

(c)

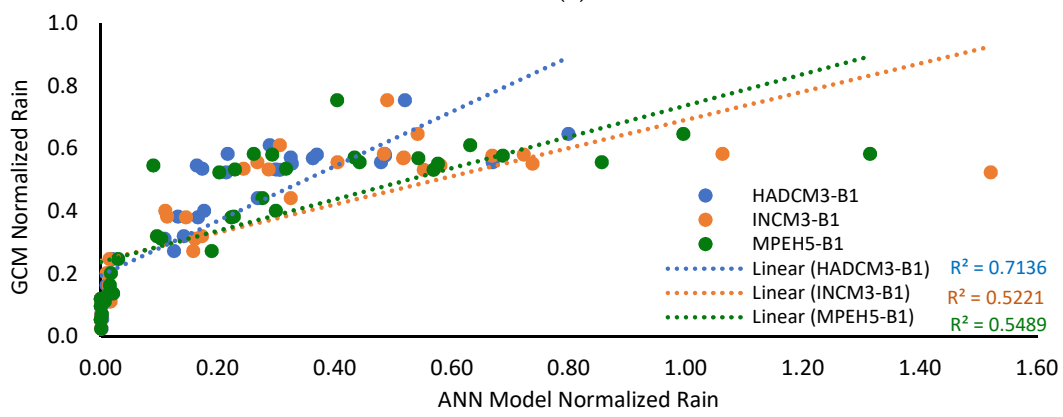

(d)

Figure 8. Comparison between ANN and GCM models with various scenarios: (a) ANN vs. ANFIS; (b) ANN vs. GCM scenario A1B; (c) ANN vs. GCM scenario A2; and (d) ANN vs. GCM scenario B1. 


\subsection{Future Predictions Using GCM/ANN}

\subsubsection{Predicted Temperature}

The predicted results indicate an increase in temperature in coming years (as shown in Figures 9-11 and Table 2). However, all three GCMs for the three scenarios indicated different increases in temperature for the periods 2011-2045, 2046-2079, and 2080-2099. The maximum increase in temperature indicated by the GCM was about 9\% with respect to the base period (1978-2011). Figures 9-11 show the annual and monthly variations of the temperature of Qassim under different emissions scenarios. It was observed that the future temperature also peaked during the period of June-September. The change in maximum temperature was in the range of $9 \%\left(2.67^{\circ} \mathrm{C}\right)$.

The various temperature values predicted for the future are given in Figures 9-11 for Qassim. The minimum, maximum, and average mean temperatures in the winter season approached $8{ }^{\circ} \mathrm{C}$, $20{ }^{\circ} \mathrm{C}$, and $15{ }^{\circ} \mathrm{C}$, respectively. The minimum, maximum, and average mean temperatures in the summer season approached $28{ }^{\circ} \mathrm{C}, 43{ }^{\circ} \mathrm{C}$, and $36^{\circ} \mathrm{C}$, respectively. The minimum, maximum, and average mean temperatures in the spring season approached $19{ }^{\circ} \mathrm{C}, 35^{\circ} \mathrm{C}$, and $27^{\circ} \mathrm{C}$, respectively. The minimum, maximum, and average mean temperatures in the autumn season approached $19{ }^{\circ} \mathrm{C}$, $36.5^{\circ} \mathrm{C}$, and $28^{\circ} \mathrm{C}$, respectively.

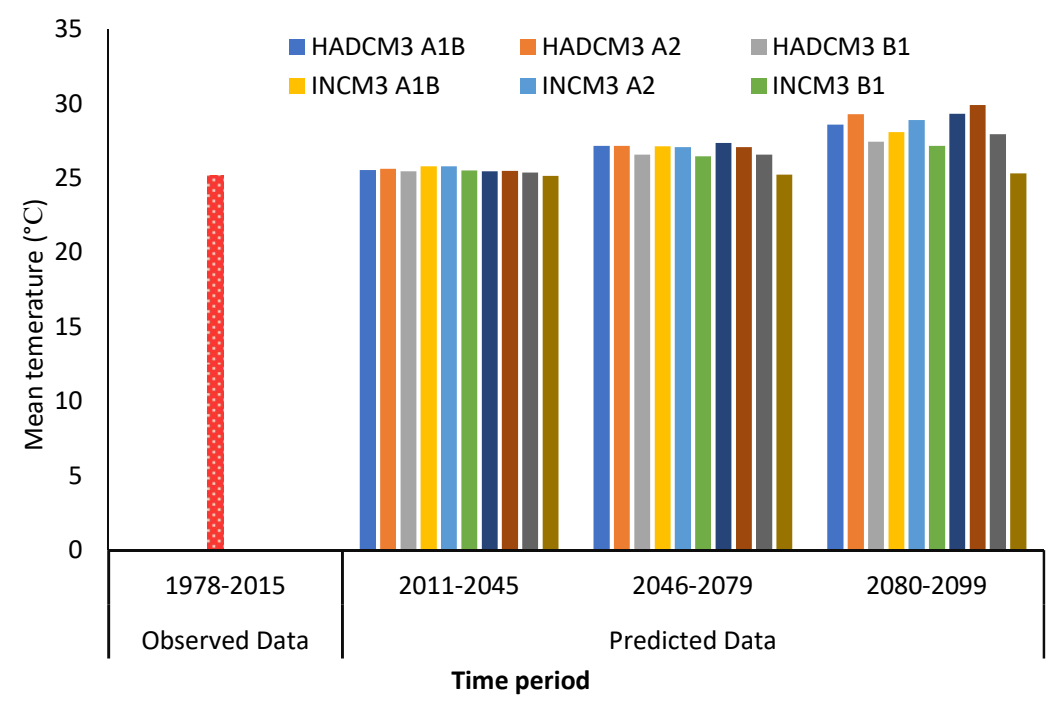

Figure 9. Annual mean temperature predicted by the various models.

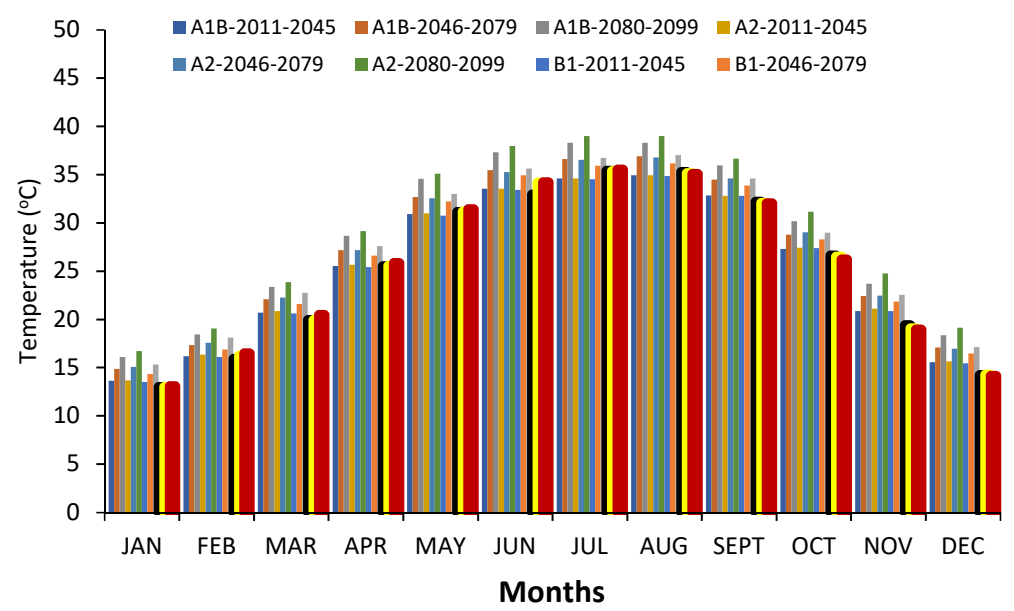

(a)

Figure 10. Cont. 


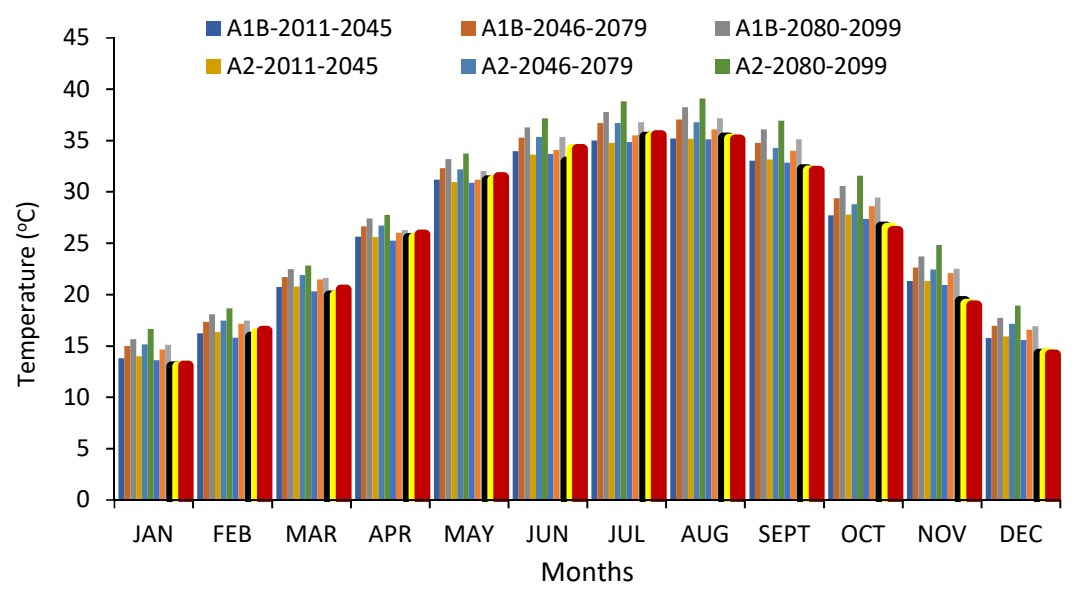

(b)

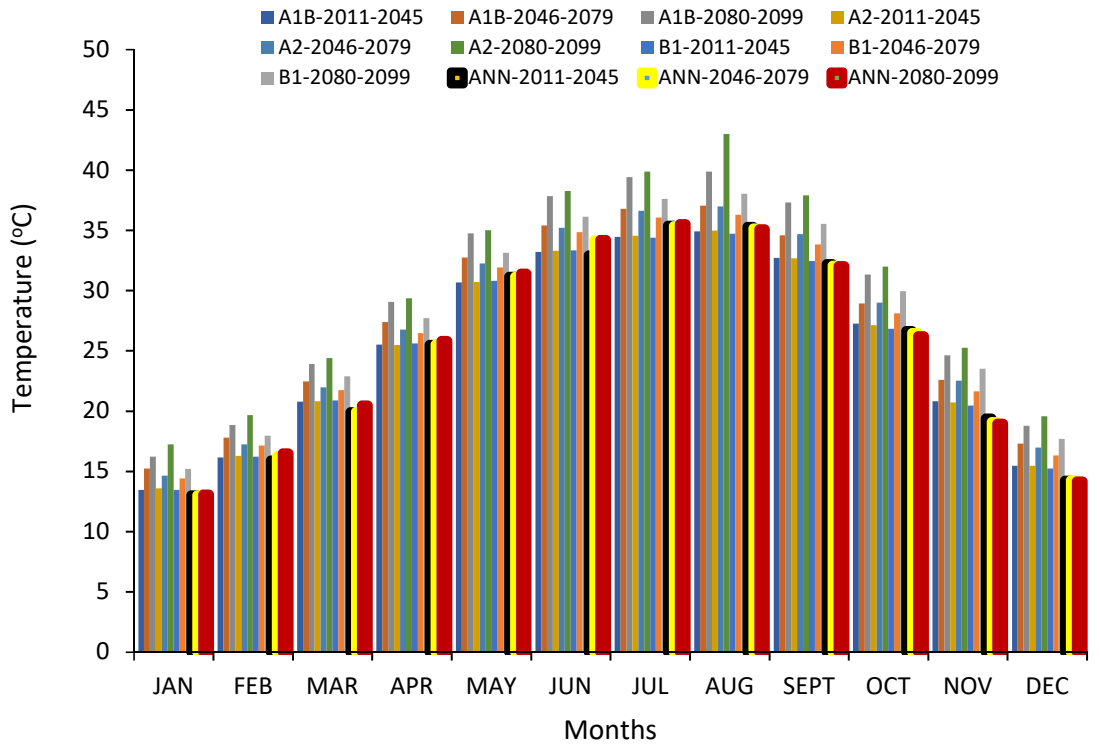

(c)

Figure 10. Temperature predicted by the ANN and various GCMs under three emissions scenarios: (a) temperature predicted by the ANN and GCM-HADCM3; (b) temperature predicted by the ANN and GCM-INCM3; and (c) temperature predicted by the ANN and GCM-MPEH5.

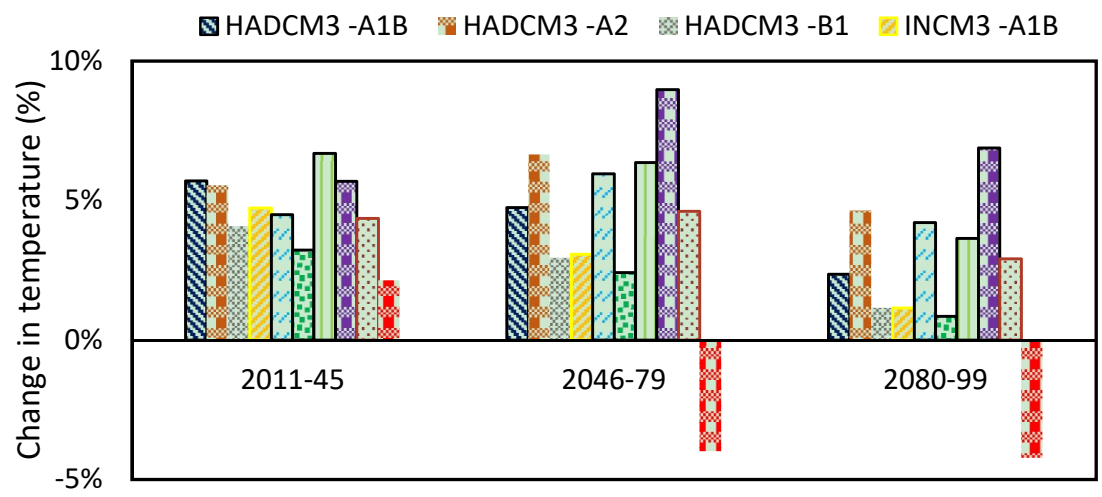

Figure 11. Mean temperature change predicted by the various models. 
Table 2. Change in rainfall $(\Delta \mathrm{P})$ in percent and temperature $(\Delta \mathrm{T})$ in percent.

\begin{tabular}{|c|c|c|c|c|c|c|c|c|c|c|c|c|}
\hline \multirow{3}{*}{ YEAR } & \multicolumn{6}{|c|}{ HADCM3 } & \multicolumn{6}{|c|}{ INCM3 } \\
\hline & $\Delta \mathrm{T}$ & $\Delta \mathbf{P}$ & $\Delta \mathrm{T}$ & $\Delta \mathbf{P}$ & $\Delta \mathrm{T}$ & $\Delta \mathbf{P}$ & $\Delta \mathrm{T}$ & $\Delta \mathbf{P}$ & $\Delta \mathrm{T}$ & $\Delta \mathbf{P}$ & $\Delta \mathrm{T}$ & $\Delta \mathbf{P}$ \\
\hline & \multicolumn{2}{|c|}{ A1B } & \multicolumn{2}{|c|}{ A2 } & \multicolumn{2}{|c|}{ B1 } & \multicolumn{2}{|c|}{ A1B } & \multicolumn{2}{|c|}{ A2 } & \multicolumn{2}{|c|}{ B1 } \\
\hline 2011-2045 & 5.7 & 17.8 & 5.5 & 17.8 & 4.1 & 18.1 & 4.7 & 20.6 & 4.5 & 4.4 & 3.2 & 3.1 \\
\hline 2046-2079 & 4.8 & 15.9 & 6.7 & -4.9 & 2.9 & 14.3 & 3.1 & -3.3 & 6.0 & 9.7 & 2.4 & 31.7 \\
\hline \multirow[t]{2}{*}{ 2080-2099 } & 2.4 & 11.4 & 4.7 & 1.8 & 1.1 & 6.9 & 1.2 & -34.8 & 4.2 & 21.9 & 0.9 & 1.3 \\
\hline & \multicolumn{6}{|c|}{ MPEH5 } & \multicolumn{6}{|c|}{ ANN } \\
\hline \multirow[t]{2}{*}{ YEAR } & $\Delta \mathrm{T}$ & $\Delta \mathbf{P}$ & $\Delta \mathrm{T}$ & $\Delta P$ & $\Delta \mathrm{T}$ & $\Delta \mathbf{P}$ & $\Delta \mathrm{T}$ & $\Delta \mathbf{P}$ & & & & \\
\hline & \multicolumn{2}{|c|}{ A1B } & \multicolumn{2}{|c|}{ A2 } & \multicolumn{2}{|c|}{ B1 } & & & & & & \\
\hline 2011-2045 & 6.7 & 17.2 & 5.7 & 18.5 & 4.4 & 16.4 & 2.1 & 3.0 & & & & \\
\hline 2046-2079 & 6.4 & -19.0 & 9.0 & -15.3 & 4.6 & 15.2 & -5.7 & -9.1 & & & & \\
\hline 2080-2099 & 3.65 & 11.2 & 6.9 & 5.1 & 2.9 & 3.0 & -3.1 & 6.8 & & & & \\
\hline
\end{tabular}

\subsubsection{Predicted Rainfall}

Regarding rainfall, no uniform trend was observed for various time spans (different changes during three different time spans of 2011-2045, 2046-2079 and 2080-2099). Figure 12 shows the results for annual rainfall predicted by the ANN and various GCMs models under three emissions scenarios. However, it can be seen in the figure that two models showed an increase in rainfall during 2011-2045 and 2080-2099, and the third, INCM3-A1B, indicated a decrease in rainfall during 2080-2099. For the period of 2046-2079 with HADCM3 under the A2 scenario, ICM3-A1B MPEH-A2, MPEH-A1B, and the ANN indicated a decrease in rainfall, and all other models showed an increase during this period. It is observed in Figure 12 that the maximum increase of about $34 \mathrm{~mm}$ (or 30\%) during 2046-2079 with respect to the base period 1978-2011 was indicated by INCM3 under the B1 scenario. The results of Tarawneh and Chowdhury [2] also revealed that different models predicted different future rainfall changes, which was in line with the results of the present research.

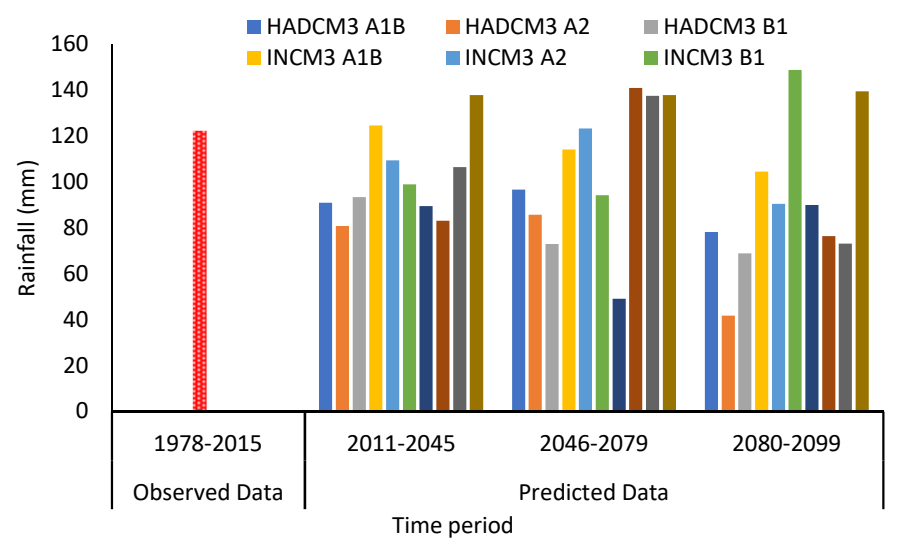

Figure 12. Annual rainfall predicted by the ANN and various GCM models under three emissions scenarios.

Figure 13 illustrates the results for predicted rainfall for three emissions scenarios using the ANN and various GCM scenarios. In the figure, the predicted rainfall had the same pattern as that of the observed records. There was no/negligible precipitation during summer and autumn, and maximum rainfall during winter was 222, 227, and $180 \mathrm{~mm}$ for 2011-2045, 2046-2079, and 2080-2099, respectively. Changes in rainfall predicted by the ANN and various GCMs are presented in Figure 14. The results showed that the percentage change in rainfall predicted in most of the cases was within an acceptable range. 


\subsection{Practicality of Results for Evaluation of Sustainability of Water Resources and Storm} Drainage Infrastructure

GCM and ANN showed an increase in temperature and changing rainfall patterns in the Qassim region. The rise in temperature entails multifold negative impacts. The increase in temperature will increase both the evaporation and water requirements in the region [2] and will be a serious cause of stress on the groundwater, which represents the main source of water in the region. Domestic water demand will therefore increase, the quality of water stored for various purposes will degrade, and agricultural water demand (crop-water requirements) will significantly increase. The rate of increase of some of these parameters with respect to temperature has been investigated in various regions around the world $[2,63,64]$. However, this can be a potential area of future research and it is recommended that research is designed to study the impact of temperature on agriculture and water demands in Qassim.

Increases in rainfall entail pros and cons as they may contribute to the sustainability of existing water resources if harvested properly. Existing storm water drainage infrastructure was designed for low intensity rainfalls with brief return periods. Therefore, increasing rainfall will increase flood risk by generating flash floods, particularly in urban areas.

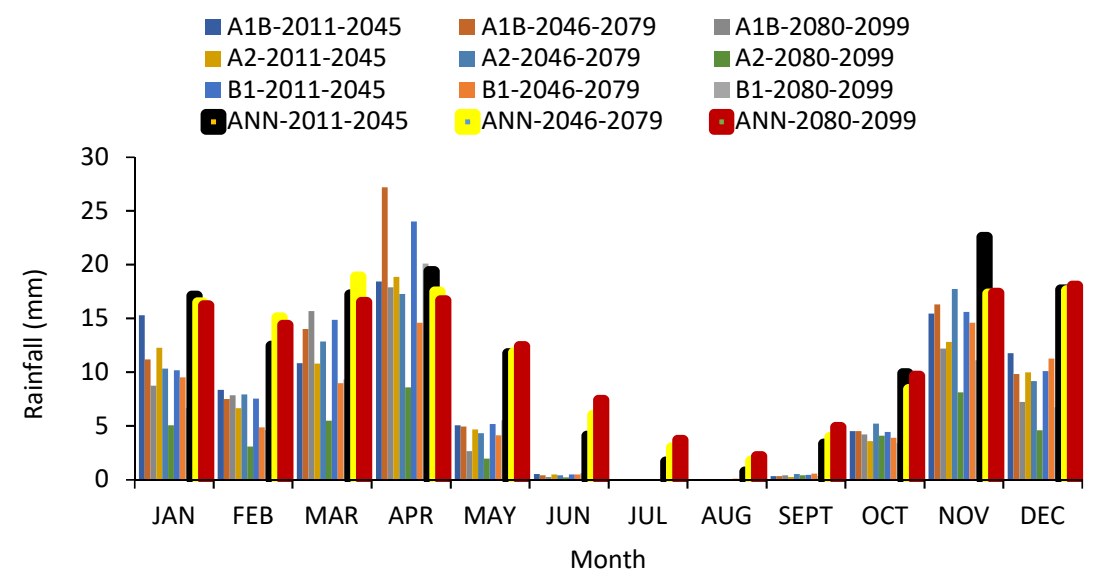

(a)

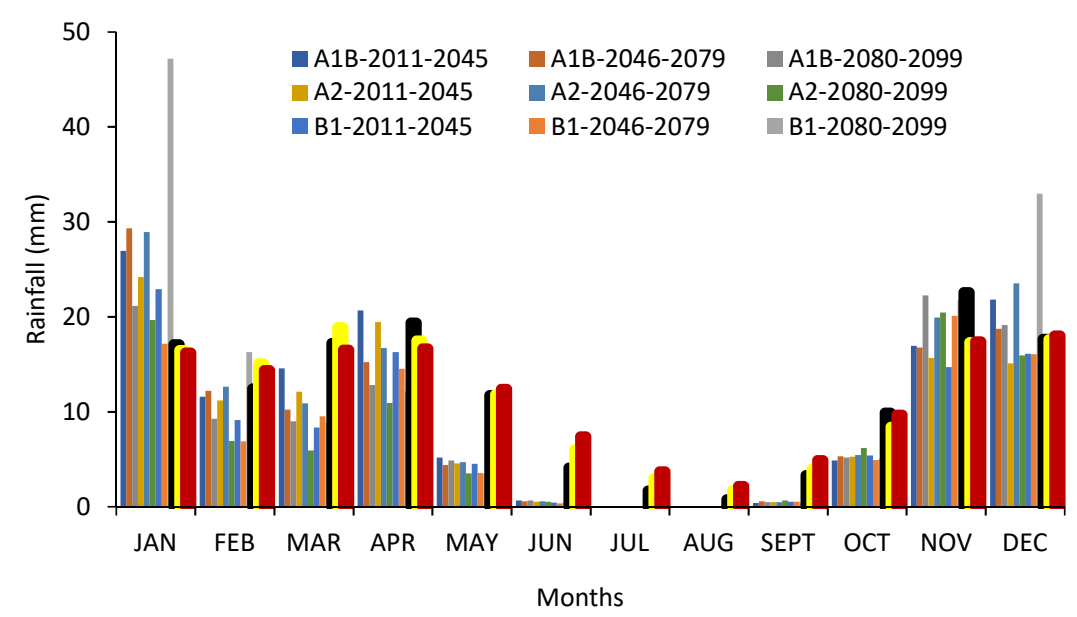

(b)

Figure 13. Cont 


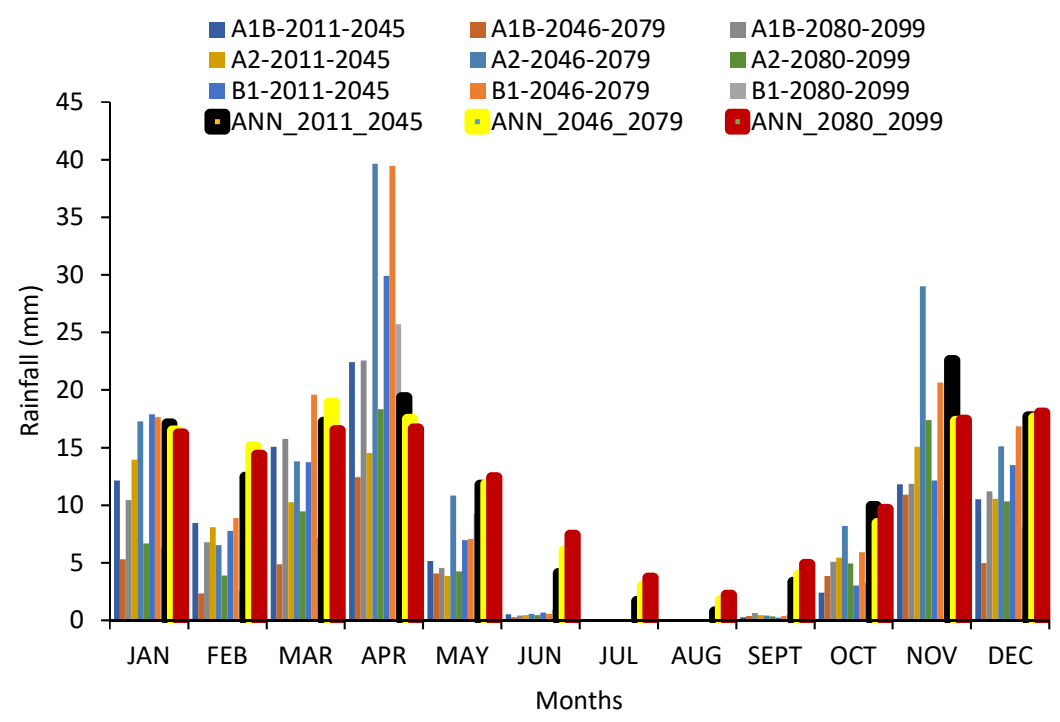

(c)

Figure 13. Rainfall predicted under three emissions scenarios using the ANN and various GCMs: (a) rainfall predicted under three emissions scenarios using the ANN and GCM-HADCM3; (b) rainfall predicted under three emissions scenarios using the ANN and GCM-INCM3; and (c) rainfall predicted under three emissions scenarios using the ANN and GCM-MPEH5.

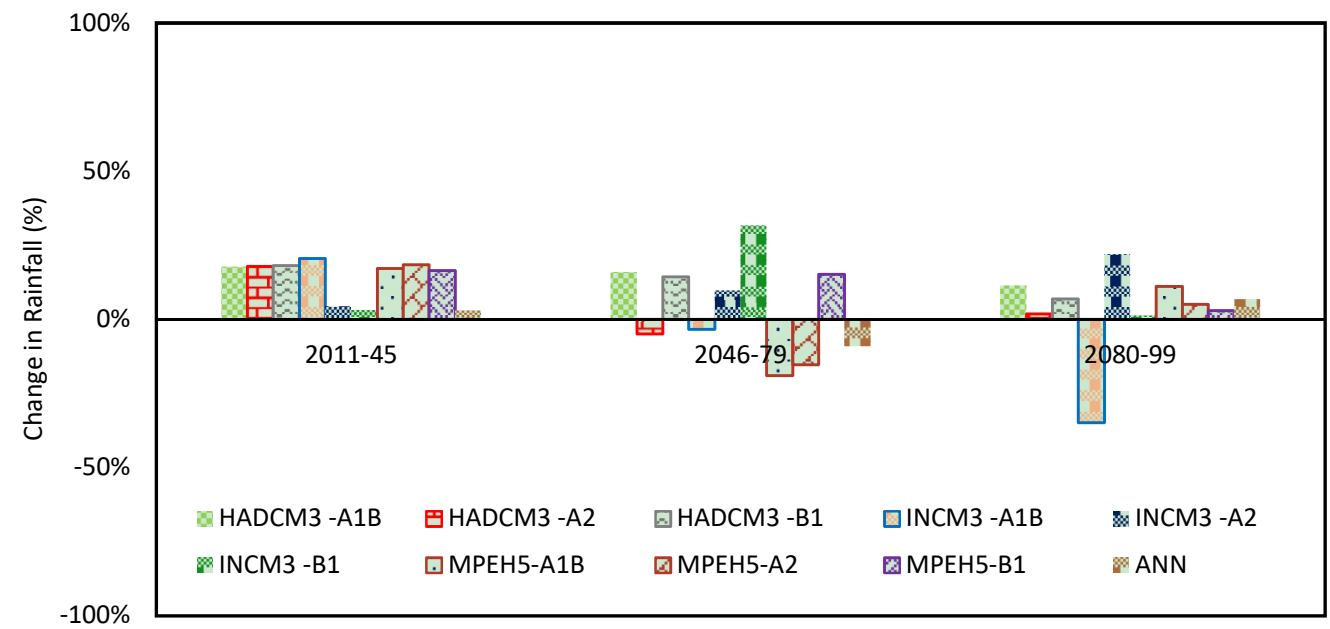

Figure 14. Change in rainfall predicted by the ANN and various GCMs.

\section{Summary, Conclusions, and Recommendations}

Rainfall and temperature changes were predicted in the Qassim region using ANNs, ANFISs, and GCMs. The results of three ANNs and three ANFISs models were compared. Three GCMs were compared with the best ANN selected from the comparison of the ANN and ANFIS. The ANN can be used for the future prediction of temperature and rainfall with reasonable accuracy when resources are too limited to run GCMs.

There was a significant variance between the results of various GCMs in climate data projections. However, the predicted results of rainfall and temperature using ANNs were reasonably close to the results of the GCM with $R^{2}$ values ranging between 0.5 and 0.7. The results of the HADCM3 with all three scenarios of A1B, A2, and B1 were comparatively closer to the ANN model-results $\left(R^{2}\right.$ nearly 0.7$)$.

The results indicate that the mean temperature of the Qassim region will increase by about $2{ }^{\circ} \mathrm{C}$ between 2011 and 2045, $3{ }^{\circ} \mathrm{C}$ between 2046 and 2079, and $2.2^{\circ} \mathrm{C}$ between 2080 and 2099. The change 
in annual rainfall will be about $28.5 \mathrm{~mm}$ during 2011-2045, $34.5 \mathrm{~mm}$ during 2046-2079, and $22 \mathrm{~mm}$ during 2080-2099 with respect to the base period.

The results of the present study are useful to the municipalities, engineers, planners, and researchers focused on water conservation, sustainable development, and flood risk management in arid environmental regions. However, it is worth mentioning that ANNs have limitations including the impact of emissions scenarios and these may be used by engineers and planners in their decision-making when the design cost of various drainage infrastructure becomes extremely high for various emissions scenarios.

Based on the findings of the present research, rainfall/runoff can be determined using rainfall intensity, watershed parameters, and evaporation/temperature for the purposes of flood risk management while considering floods with longer return periods. There are about 17 dams in the Qassim region that can be used for rainwater harvesting in several ways. The stored water can be utilized for crops, drinking, and recharging the groundwater following its proper treatment. For rainfall increases in the range of 1-34 mm, the increase in the runoff will be nearly the same as the level of change in rainfall as runoff is directly proportional to rainfall intensity.

It is recommended to begin collecting data regarding runoff and to perform modeling to achieve better investigations of water resources in the region.

Author Contributions: K.A. worked on methodology, formal analysis and software. A.R.G. contributed to conceptualization, writing the original draft, supervision and validation. H.H. helped in reviewing and editing the manuscript, visualization and investigations. Y.M.G. worked on data curation and project administration. M.S. contributed to data curation and analysis.

Funding: No funding was received from any quarter.

Acknowledgments: The authors are thankful to I.S.A.S., Head of Civil Engineering Department, College of Engineering, Qassim University for his continued encouragement in completing this research work. We are thankful to all faculty members of Civil Engineering Department, College of Engineering, Qassim University Saudi Arabia for their moral support to make this research work possible.

Conflicts of Interest: The authors declare no conflict of interest.

\section{References}

1. Krysanova, V.; Vetter, T.; Eisner, S.; Huang, S.; Pechlivanidis, I.; Strauch, M.; Gelfan, A.; Kumar, R.; Aich, A.; Arheimer, B.; et al. Inter-comparison of regional-scale hydrological models and climate change impacts projected for 12 large river basins worldwide-A synthesis. Environ. Res. Lett. 2017, 12. [CrossRef]

2. Tarawneh, Q.Y.; Chowdhury, S. Trends of climate change in Saudi Arabia: Implications on water resources. Climate 2018, 6, 8. [CrossRef]

3. Collins, M.; Knutti, R.; Arblaster, J.; Dufresne, J.L.; Fichefet, T.; Friedlingstein, P. Long-term Climate Change: Projections, Commitments and Irreversibility. In Climate Change 2013: The Physical Science Basis. Contribution of Working Group I to the Fifth Assessment Report of the Intergovernmental Panel on Climate Change; Stocker, T.F., Qin, D., Plattner, G.K., Tignor, M., Allen, S.K., Boschung, J., Nauels, A., Xia, Y., Bex, V., Midgley, P.M., Eds.; Cambridge University Press: Cambridge, UK; New York, NY, USA, 2013; pp. 1029-1136.

4. IPCC. 2013: Summary for Policymakers. The Physical Science Basis. Contribution of Working Group I to the Fifth Assessment Report of the Intergovernmental Panel on Climate Change. In Climate Change 2013; Stocker, T.F., Qin, D., Plattner, G.K., Tignor, M., Allen, S.K., Boschung, J., Nauels, A., Xia, Y., Bex, V., Midgley, P.M., Eds.; Cambridge University Press: Cambridge, UK; New York, NY, USA, 2013; pp. 1-30.

5. Zhang, H.; Zhang, L.L.; Li, J.; An, R.D.; Deng, Y. Climate and Hydrological Change Characteristics and Applicability of GLDAS Data in the Yarlung Zangbo River Basin, China. Water 2018, 10, 254. [CrossRef]

6. Al Zawad, F.M. Impacts of Climate Change on Water Resources in Saudi Arabia. In Proceedings of the 3rd International Conference on Water Resources and Arid Environments (2008) and the 1st Arab Water Forum, King Fahd Cultural Centre, Riyadh, Saudi Arabia, 16-19 November 2008.

7. Hattermann, F.F.; Krysanova, V.; Gosling, S.; Dankers, R.; Daggupati, P.; Donnelly, C.h.; Flörke, M.; Huang, S.; Motovilov, Yu.; Buda, S.; et al. Cross-scale inter-comparison of climate change impacts simulated by regional and global hydrological models in eleven large river basins. Clim. Change 2017, 141, 561-576. [CrossRef] 
8. Peng, Y.; Zhao, X.; Wu, D.; Tang, B.; Xu, P.; Du, X.; Wang, H. Spatiotemporal variability in extreme precipitation in China from observations and projections. Water 2018, 10, 1089. [CrossRef]

9. Mekonnen, D.F.; Disse, M. Analyzing the future climate change of Upper Blue Nile River basin using statistical downscaling techniques. Hydr. Earth Syst. Scie. 2018, 22, 2391-2408. [CrossRef]

10. Sørland, S.L.; Schar, C.; Luthi, D.; Kjellstrom, E. Bias patterns and climate change signals in GCM, RCM model chains. Environ. Res. Lett. 2018, 13, 74017. [CrossRef]

11. Bucchignani, E.; Mercogliano, P.; Panitz, H.J.; Montesarchio, M. Climate change projections for the Middle East-North Africa domain with COSMO-CLM at different spatial resolutions. Adv. Clim. Change Res. 2018, 9, 66-80. [CrossRef]

12. Raneesh, K.Y. Impact of Climate Change on Water Resources. J. Earth Sci. Clim. Chang. 2014, 5, 185. [CrossRef]

13. Gao, X.Y.; Shi, D.; Zhang, J.; Wu, F.; Giorgi, Z.J.; Wang, Y. Uncertainties in monsoon precipitation projections over China: Results from two high-resolution RCM simulations. Clim. Res. 2012, 52, 213-226. [CrossRef]

14. Wang, Y.; Sivandran, G.; Bielicki, J.M. The stationarity of two statistical downscaling methods for precipitation under different choices of cross-validation periods. Int. J. Climatol. 2018, 38, 330-348. [CrossRef]

15. Zobel, Z.; Wang, J.; Wuebbles, D.J.; Kotamarthi, V.R. High-Resolution Dynamical Downscaling Ensemble Projections of Future Extreme Temperature Distributions for the United States. Earths Future 2017, 5, 1234-1251. [CrossRef]

16. Lewis, J.; Bodeker, G.E.; Tait, A.; Kremser, S. A method to encapsulate model structural uncertainty in ensemble projections of future climate. Geosci. Model. Dev. 2017, 10, 4563-4575. [CrossRef]

17. Sharma, T.; Vittal, H.; Chhabra, S.; Salvi, K.; Ghosh, S.; Karmakar, S. Understanding the cascade of GCM and downscaling uncertainties in hydro-climatic projections over India. Int. J. Climatol. 2018, 38, e178-e190. [CrossRef]

18. Zelazowski, P.; Huntingford, C.; Mercado, L.M.; Schaller, N. Climate pattern-scaling set for an ensemble of 22 GCM-Adding uncertainty to the IMOGEN version 2.0 impact system. Geosci. Model. Dev. 2018, 11, 541-560. [CrossRef]

19. Patrick, A.R.; Brown, C.M. Confronting Climate Uncertainty in Water Resources Planning and Project Design: The Decision Tree Framework; World Bank: Washington, DC, USA, 2015. [CrossRef]

20. Hall, J. Probabilistic climate scenarios may misrepresent uncertainty and lead to bad adaptation decisions. Hydr. Processes 2007, 21, 1127-1129. [CrossRef]

21. Fekete, B.; Vorosmarty, C.; Roads, J.; Willmott, C. Uncertainties in precipitation and their impacts on runoff estimates. J. Clim. 2004, 17, 294-304. [CrossRef]

22. Brown, C.; Wilby, R.L. An alternate approach to assessing climate risks. EOS 2012, 93, 401-412. [CrossRef]

23. Liu, P.; Qiu, X.; Yang, Y.; Ma, Y.; Jin, S. Assessment of the performance of three dynamical climate downscaling methods using different land surface information over china. Atmos. 2018, 9, 2. [CrossRef]

24. Hassan, I.; Ghumman, A.R. Application of civil engineering softwares for downscaling GCM results. Int. Invent. J. Eng. Sci. Technol. 2015, 2, 1-9.

25. Jiang, Y.; Kim, J.B.; Still, C.J.; Kerns, B.K.; Kline, J.D.; Cunningham, P.G. Inter-comparison of multiple statistically downscaled climate datasets for the Pacific Northwest, USA. Sci. Data 2018, 5, 180016. [CrossRef] [PubMed]

26. Luo, M.; Liu, T.; Frankl, A.; Duan, Y.; Meng, F.; Bao, A.; Kurban, A.; Maeyer, P.D. Defining spatiotemporal characteristics of climate change trends from downscaled GCM ensembles: How climate change reacts in Xinjiang, China. Int. J. Climatol. 2018, 38, 2538-2553. [CrossRef]

27. Byun, K.; Hamlet, A.F. Projected changes in future climate over the Midwest and Great Lakes region using downscaled CMIP5 ensembles. Int. J. Climatol. 2018, 38, e531-e553. [CrossRef]

28. Soosani, S.V.J.; Adeli, K.; Fadaei, H.; Naghavi, H.; Pham, T.D.; Bui, D.T. Improving accuracy estimation of forest aboveground biomass based on incorporation of ALOS-2 PALSAR-2 and sentinel-2A imagery and machine learning: A case study of the Hyrcanian forest area (Iran). Remote Sens. 2018, 10, 172. [CrossRef]

29. Pham, T.D.; Yoshino, K.; Bui, D.T. Biomass estimation of Sonneratia caseolaris (L.) Engler at a coastal area of Hai Phong city (Vietnam) using ALOS-2 PALSAR imagery and GIS-based multi-layer perceptron neural networks. GISci. Remote Sens. 2016, 54, 329-353. [CrossRef]

30. Kovačević, M.; Ivanišević, N.; Dašić, T.; Marković, L. Application of artificial neural networks for hydrological modeling in karst. Građevinar 2018, 70, 1-10. [CrossRef] 
31. Kyada, P.M.; Kumar, P. Daily Rainfall Forecasting Using Adaptive Neurofuzzy Inference System (ANFIS) Models. Int. J. Sci. Nat. 2015, 6, 382-388.

32. Alfarisy, G.A.F.; Mahmudy, W.F. Rainfall Forecasting in Banyuwangi Using Adaptive Neuro Fuzzy Inference System. J. Inf. Technol. Comput. Sci. 2016, 1, 65-71. [CrossRef]

33. Ghorbani, M.A.; Zadeh, H.A.; Isazadeh, M.; Terzi, O. A comparative study of artificial neural network (MLP, RBF) and support vector machine models for river flow prediction. Environ. Earth Sci. 2016, 75, 1-14. [CrossRef]

34. Granata, F.; Gargano, R.; de Marinis, G. Support vector regression for rainfall-runoff modeling in urban drainage: A comparison with the EPA's storm water management model. Water 2016, 8, 69. [CrossRef]

35. Hosseini, S.M.; Mahjouri, N. Integrating support vector regression and a geomorphologic artificial neural network for daily rainfallrunoff modeling. J. Appl. Soft Comput. 2016, 38, 329-345. [CrossRef]

36. Adnan, R.M.; Yuan, X.; Kisi, O.; Anam, R. Improving accuracy of river flow forecasting using LSSVR with Gravitational Search Algorithm. Adv. Meteorol. 2017, 2017, 1-23. [CrossRef]

37. Chang, C.C.; Lin, C.J. LIBSVM: A library for support vector machines. J. ACM TIST. 2011, 2, 27. [CrossRef]

38. Zaini, N.; Malek, M.A.; Yusoff, M.; Mardi, N.H.; Norhisham, S. daily river flow forecasting with hybrid support vector machine-Particle swarm optimization. IOP Conf. Ser. Earth Environ. Sci. 2018, 140, 012035. [CrossRef]

39. Londhe, S.N.; Gavraskar, S. Stream flow forecasting using least square support vector regression. J. Soft Comput. Civ. Eng. 2018, 2, 56-88.

40. Ali, Z.; Hussain, I.; Faisal, M.; Nazir, M.H.; Hussain, T.; Shad, M.Y.; Shoukry, M.A.; Gani, S.H. Forecasting drought using multilayer perceptron artificial neural network model. Adv. Meteorol. 2017, 2017, 1-9. [CrossRef]

41. Mishra, N.; Soni, H.K.; Sharma, S.; Upadhyay, A.K. Development and analysis of artificial neural network models for rainfall prediction by using time-series data. Int. J. Intell. Syst. Appl. 2018, 1, 16-23. [CrossRef]

42. Forestieri, A.; Arnone, E.; Blenkinsop, S.; Candela, A.; Fowler, H.; Noto, L.V. The impact of climate change on extreme precipitation in Sicily, Italy. Hydrol. Process. 2018, 32, 332-348. [CrossRef]

43. Saymohammadi, S.; Zarafshani, K.; Tavakoli, M.; Mahdizadeh, H.; Amiri, F. Prediction of climate change induced temperature \& precipitation: the case of iran. Sustainability 2017, 9, 146. [CrossRef]

44. Chowdhury, S.; Al-Zahrani, M.; Abbas, A. Implications of climate change on crop water requirements in arid region: An example of Al-Jouf, Saudi Arabia. Arab. J. Sci. Eng. 2016, 38, 1959-1971. [CrossRef]

45. DeNicola, E.; Aburizaiza, O.S.; Siddique, A.; Khwaja, H.; Carpenter, D.O. Climate change and water scarcity: The case of Saudi Arabia. Ann. Glob. Health 2015, 21, 342-353. [CrossRef] [PubMed]

46. Hassan, I.; Abdul, R.G.; Hashim, N.H.; Abdul, S.S. Investigation of the impact of global warming on precipitation pattern of Saudi Arabia. Civ. Eng. Environ. Syst. 2009, 27, 365-376. [CrossRef]

47. Almazroui, M. Simulation of present and future climate of Saudi Arabia using a regional climate model (PRECIS). Int. J. Climatol. 2013, 33, 2247-2259. [CrossRef]

48. Alhumaid, M.; Ghumman, A.R.; Haider, H.; Al-Salamah, I.S.; Ghazaw, Y.M. Sustainability evaluation framework of urban stormwater drainage options for arid environments using hydraulic modeling and multicriteria decision-making. Water 2018, 10, 581. [CrossRef]

49. Jain, A.; Varshney, A.K.; Joshi, U.C. Short-term water demand forecast modelling at IIT Kanpur using artificial neural networks. Water Resources Manag. 2001, 15, 299-321. [CrossRef]

50. Rezaeianzadeh, M.; Tabari, H.; Yazdi, A.A.; Isik, S.; Kalin, L. Flood flow forecasting using ANN, ANFIS and regression models. Neural Comput. Applic. 2014, 25, 25-37. [CrossRef]

51. Maind, S.B.; Wankar, P. Research paper on basic of artificial neural network. Int. J. Recent Innov. Trends Comput. Commun. 2014, 2, 96-100.

52. Zahmatkesh, Z.; Goharian, E. Comparing machine learning and decision making approaches to forecast long lead monthly rainfall: The city of Vancouver, Cana. Hydrology 2018, 5, 10. [CrossRef]

53. Zhou, J.; Peng, T.; Zhang, C.; Sun, N. Data pre-analysis and ensemble of various artificial neural networks for monthly streamflow forecasting. Water 2018, 10, 628. [CrossRef]

54. El-Shafie, A.; Jaafer, O.; Akrami, S.A. Adaptive neuro-fuzzy inference system based model for rainfall forecasting in Klang River, Malaysia. Int. J. Phys. Sci. 2011, 6, 2875-2888. [CrossRef] 
55. Sanderson, M.; Arbuthnott, K.; Kovats, S.; Hajat, S.; Falloon, P. The use of climate information to estimate future mortality from high ambient temperature: A systematic literature review. PLoS ONE 2017, 12, e0180369. [CrossRef] [PubMed]

56. Leggett, J.; Pepper, W.J.; Swart, R.J.; Edmonds, J.; Meira, L.G.; Mintzer, I.; Wang, M.X.; Wasson, J. Emissions scenarios for the IPCC: an update. Climate Change 1992: The Supplementary Report to the IPCC Scientific Assessment; Cambridge University Press: Cambridge, UK, 1992.

57. Nakicenovic, N.; Swart, R. IPCC: Special Report on Emissions Scenarios; Cambridge University Press: Cambridge, UK, 2000.

58. Moss, R.H.; Edmonds, J.A.; Hibbard, K.A.; Manning, M.R.; Rose, S.K.; van Vuuren, D.P.; Carter, T.R.; Emori, S.; Kainuma, M.; Kram, T.; et al. The next generation of scenarios for climate change research and assessment. Nature 2010, 463, 747-756. [CrossRef] [PubMed]

59. Ritchie, J.; Dowlatabadi, H. Defining climate change scenario characteristics with a phase space of cumulative primary energy and carbon intensity. Environ. Res. Lett. 2018, 13, 024012. [CrossRef]

60. Ponce, V.M. Engineering Hydrology: Principles and Practices, 2nd ed.; Prentice Hall: Englewood Cliffs, NJ, USA, 1989.

61. Mutreja, K.M. Hydrologic synthesis and simulation. In Applied Hydrology, 2nd ed.; Tata McGraw-Hill. Inc.: London, UK, 1986; pp. 613-668.

62. Hasanean, H.; Almazroui, M. Rainfall: Features and variations over saudi arabia, a. review. Climate 2015, 3, 578-626. [CrossRef]

63. Alkolibi, F.M. Possible effects of global warming on agriculture and water resources in Saudi Arabia: Impacts and responses. Clim. Chang. 2002, 54, 225-245. [CrossRef]

64. Tekeli, A.E. Exploring Jeddah floods by tropical rainfall measuring mission analysis. Water 2017, 9, 612. [CrossRef]

(C) 2018 by the authors. Licensee MDPI, Basel, Switzerland. This article is an open access article distributed under the terms and conditions of the Creative Commons Attribution (CC BY) license (http:/ / creativecommons.org/licenses/by/4.0/). 